\title{
Inhalation exposure to various nanoparticles in work environment - contextual information and results of measurements
}

\author{
Przemyslaw Oberbek (D) Pawel Kozikowski • \\ Katarzyna Czarnecka • Piotr Sobiech • \\ Szymon Jakubiak • Tomasz Jankowski
}

Received: 3 May 2019 / Accepted: 30 August 2019/Published online: 28 October 2019

(C) The Author(s) 2019

\begin{abstract}
Outside the wide range of potential benefits, the use of nanomaterials can endanger human health, mostly through skin contact and the risk of inhalation. This article presents the results of harmonized measurements with contextual information on the emission of nanoparticles during the manufacturing and application of nanotechnology products. The purpose of the research was to investigate the actual levels of exposure to nano-objects in real working conditions in chosen Polish companies. Measurements were carried out in
\end{abstract}

P. Oberbek $(\bowtie) \cdot$ P. Kozikowski · P. Sobiech •

S. Jakubiak $\cdot$ T. Jankowski

Department of Chemical, Biological and Aerosol Hazards, Central Institute for Labour Protection - National Research Institute,

Czerniakowska 16, 00-701 Warsaw, Poland

e-mail: ober@ciop.pl

P. Kozikowski

e-mail: pakoz@ciop.pl

P. Sobiech

e-mail: pisob@ciop.pl various workplaces: during silver nanoparticle synthesis, production of thin nanocarbon layers, 3D-printing with the use of a nanohydroxyapatite-polymer composite and the production of special seals from thin glass foils. Research was conducted on the basis of task-based measurements and offline microscopic analysis. Realtime particle DiSCmini counters were used to determine the nano-object concentration during different processes and events: samplers for collecting air dust, and a scanning electron microscope to confirm the presence of

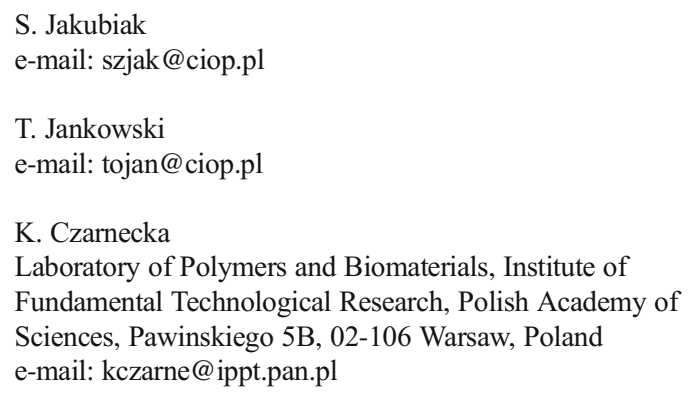


nanoparticles emitted from selected sources. Average particle sizes obtained with analysis of microscopic images were as follows: $46.7 \pm 13.4 \mathrm{~nm}, 19.8 \pm$ $4.8 \mathrm{~nm}, 22.4 \pm 7.6 \mathrm{~nm}, 49.2 \pm 26.3 \mathrm{~nm}$ respectively for workplaces. The concentration during significant events was referred to the background particle level. During one of the repeated processes, an unexpected and extremely high nanoparticle emission was recorded, which, in the long run, could cause a health hazard to workers. The studies have shown the importance of collective protective measures, revealed unexpected sources of accidentally generated nanoparticles and allowed to obtain knowledge about levels of exposure to nanoparticles during the various processes.

Keywords Nanoparticles · Ultrafine particles ·

Occupational exposure $\cdot$ Field monitoring $\cdot$ Occupational health $\cdot$ Real-time measurement

\section{Introduction}

\section{Nanomaterials}

Nanomaterials in the form of nano-objects, their aggregates or agglomerates (NOAA) have found a wide range of applications in many sectors and products. They are structures up to 10,000 times smaller than the diameter of a human hair. This scale is comparable to that of viruses, molecules or even atoms. In Europe, the definition of the nanoscale was given by International Organization for Standardization (ISO), cooperating with the European Committee for Standardization (CEN), as a size range from approximately 1 to $100 \mathrm{~nm}$ (Definition of a nanomaterial 2017; EU 2011).

It is also important to introduce the ultrafine particles (UFPs), a term used when referring to naturally occurring nanomaterials. UFPs are the fraction of ambient particulate matter $\left(\mathrm{PM}_{0.1}\right)$, containing airborne particles of nanoscale size with a diameter $<0.1 \mu \mathrm{m}$ (HEI 2013). UFPs are highly related to the anthropogenic emission sources (power plants, combustion engines) or natural emission sources.

Matter in the nanoscale gains new chemical, biological, mechanical and physical properties, with material properties and desired performance often enhanced in relation to its microscale equivalent. Engineered nanomaterials (ENMs) have found applications in many sectors, including aerospace, automobile, chemical, construction, cosmetics, electronics, energy, engineering, environment, food, medicine, security, sports, telecommunication, textiles and transportation (Buzea et al. 2007; Dastjerdi and Montazer 2010; Dolez 2015; Dreaden et al. 2012; Firdhouse and Lalitha 2015; Gajanan and Tijare 2018; Prasad et al. 2017; Ramos et al. 2017; Salata 2004; Simcha et al. 2012; Xie et al. 2012; Zhang et al. 2013). Nanotechnology is often seen as one of the critical technological breakthroughs of the twenty-first century.

Health concerns

Apart from its numerous benefits, the use of engineered nanomaterials (or manufactured nanomaterials - name used interchangeably) can also endanger human health, mainly because of their potential toxicity (Buzea et al. 2007; Gomez et al. 2014; Hoet et al. 2004; Jeevanandam et al. 2018; Khanna et al. 2015; Nogueira et al. 2014). The respiratory system is considered to be one of the major routes of exposure for humans (SCENIHR 2007). Nano-objects with a diameter less than $100 \mathrm{~nm}$ deposit in larger airways and in the alveolar region of the lung with high efficiency (Heyder 2004; Heyder et al. 1986).

Because of their size, the inhaled nanoscale objects can reach the bloodstream, pass through biological membranes, accumulate in organs and cross the bloodbrain barrier (Al-Sid-Cheikh et al. 2018; Cheng et al. 2013; De Jong and Borm 2008; Mc Carthy et al. 2015; Nel et al. 2006; Sobot et al. 2014; Terentyuk 2009). They can be internalized by living cells and affect basic cellular processes like metabolism, proliferation, differentiation or lysis (Singh and Nalwa 2007); moreover, they are not well recognized and disposed of by macrophages (Oberdörster et al. 1992). Employees of nanotechnology companies are the largest social group to have physical contact with NOAA and UFPs. Workplace exposure can occur at different stages of the supply chain (during production, processing, transport, packaging, quality control, etc.) and originate from different sources, e.g. fork lift trucks heating units, vacuum cleaners, engines exhaust, cutting, screening, transport, mixing, blending, grinding and polishing (EC 2014; Jeevanandam et al. 2018), meaning that the workers may not even be aware of the fact of exposure. The worst-case scenarios concern the production of nanoparticles in dry powder state and accidental leakage or spill during the manufacturing process (O'Shaughnessy 2013). 
Exposure assessment strategies for NOAA

As a main part of the risk management strategy, it is very important to study the potential inhalation exposure associated with the accidental UFP emission, as well as production, processing and handling of ENMs in a workplace environment. For chemical and dust hazards with known occupational exposure limits (OELs) or workplace exposure limits (WELs) (Deveau et al. 2015) at the workplace, gravimetric sampling with airborne particles filter collection is used. Because of their minor impact on the overall mass concentration, the NOAA are difficult to assess using this approach. It is worth noting that the mass of one particle with a diameter of $10 \mu \mathrm{m}$ corresponds to the mass of $10^{9}$ particles with a diameter of $10 \mathrm{~nm}$. The total mass of the particles contained in the aerosol may constitute only its percentage, but their number can reach over $80 \%$ of the total particles. Therefore, ENM and UFP emissions are usually characterized by number concentration (particles/ $\mathrm{cm}^{3}$ ) (Lavoie 2010) and mass concentration-based approach is less frequently used.

Currently, there are no specific international regulations for various ENMs and UFPs. There are also no occupational exposure limits imposed by European law for NOAA. However, there are general rules and recommendations to protect the workers, proposed by US National Institute for Occupational Safety and Health (Christine M. Branche 2009; NIOSH 2011), Organisation for Economic Co-operation and Development (OECD 2017), International Organization for Standardization (ISO 2012b, 2014) and several other institutions, organizations and government bodies. In many documents, reference values and methods for determining safe levels of exposure have been proposed. Three main approaches to exposure assessment can be distinguished:

- Reference of safe values of nanomaterials to the safe values of their larger counterparts (bulk material) (see "Pragmatic guidance levels based on the OELs or WELs of the bulk materials")

- Setting specific maximum concentration values (safe exposure levels) for groups of nanomaterials or selected nanocompounds (see "Recommended safe exposure levels for NOAA"),

- Task-based measurements - a comparison of the results of the concentration measurements from the studied activities to the average value of the concentration of the background nanoparticles (see "Task-based exposure assessment").

Pragmatic guidance levels based on the OELs or WELS of the bulk materials

In 2007, the British Standards Institution (BSI) published a document recommending in the exposure assessment to use a specific part of the WEL dose (depending on the type of substance) as an acceptable level of exposure, to determine the benchmark exposure levels (BELs).

BELs were set for four groups of nanomaterials based on consideration of their typical hazard severity: nanomaterials classified as carcinogenic, mutagenic, asthmagenic or reproductive toxins (CMAR, BEL $=$ $0.1 \times$ WEL of the bulk material), insoluble nanomaterials (BEL $=0.066 \times$ WEL of the bulk material), soluble nanomaterials $(\mathrm{BEL}=0.5 \times \mathrm{WEL}$ of the bulk material), fibrous nanomaterials $(B E L=0.01$ fibres $/ \mathrm{cm}^{3}$ ) (BSI 2007; OECD 2017). These proposed values were intended as pragmatic guidance levels and were not assumed to be safe WELs. Later, Benke et al. (Geza Benke 2010) examined the BEL groups and recommended that the BEL for insoluble or poorly soluble fibrous nanomaterials should be 0.1 fibre $/ \mathrm{cm}^{3}$, rather than the 0.01 fibre $/ \mathrm{cm}^{3}$.

Since the values were based on existing OELs or WELs, they were not applicable for materials without derived safe levels. Therefore, an approach based on pragmatic guidance levels did not gain much popularity and was criticized (Broekhuizen and Hendrikx 2013; Kumar et al. 2010; Mark 2007). BSI also proposed an alternative approach with a number-based levels (see "Recommended safe exposure levels for NOAA").

\section{Recommended safe exposure levels for NOAA}

The average concentration of nanomaterials in workplace environment could be described using metrics such as mass per volume or number of particulates (or fibres) per volume. Few countries and companies have undertaken to set threshold mass concentrations for the specific nanomaterials. The World Health Organization (WHO) gathered guidelines and specific recommendations on control exposure to NOAA. The WHO report presents and describes proposed OELs that are publicly available (WHO 2017). In 2017, Mihalache and co- 
workers identified 20 studies that proposed 56 occupational exposure limit values for EMNs (Mihalache et al. 2017). One year later, the same number of OELs was reported at the American Conference of Governmental Industrial Hygienists (ACGIH 2018). For example, the US NIOSH set $0.3 \mathrm{mg} / \mathrm{m}^{3}$ (10 h TWA-time weighted average - per day during a 40-h work week) as a recommended exposure limit (REL) for ultrafine and nanoscale $\mathrm{TiO}_{2}$ and REL of $1.0 \mu \mathrm{g} / \mathrm{m}^{3}$ for carbon nanotubes (CNTs) (Ellenbecker et al. 2018; NIOSH 2011; NIOSH 2013). A value of $0.3 \mathrm{mg} / \mathrm{m}^{3}$ might be used as a default value if there is no other data on specific nanomaterial. This value has also been proposed as a reduced general threshold value for respirable dusts in Germany (DFG 2011). BASF SE company set a no-observed-effect level (NOEL) for carbon nanotubes (CNT) at $0.1 \mathrm{mg} /$ $\mathrm{m}^{3}$ (Ma-Hock et al. 2009). The Nanocyl company in Belgium uses a NOEL value of $2.5 \mu \mathrm{g} / \mathrm{m}^{3}$ for multiwalled CNTs (Schulte et al. 2010). Based on subchronic 13-week inhalation exposure of rats to multiwalled CNTs Bayer company set for them an OEL of $50 \mu \mathrm{g} /$ $\mathrm{m}^{3}$ (for 8-h TWA during a 40-h work week) (Pauluhn 2010a, b).

There are also countries where yet no official OELs are set for nanomaterials, but national institutes are conducting researches on biological effects of chosen nanoparticles and recommend specific safe levels. For example, the Polish Nofer Institute of Occupational Medicine proposed MAC-TWA (maximum admissible concentration-the time-weighted average) of $10 \mu \mathrm{g} / \mathrm{m}^{3}$ for nanosilver and $300 \mu \mathrm{g} / \mathrm{m}^{3}$ for nano $\mathrm{TiO}_{2}$ (Świdwińska-Gajewska and Czerczak 2014; Świdwińska-Gajewska and Czerczak 2015).

Properties of nano-objects such as their surface area, particle number concentration, or fibre aspect ratio are considered to be better metrics of exposure than mass concentration (Christine M. Branche 2009; Mark 2007; Maynard and Aitken 2007). For insoluble nanomaterials, BSI proposed particle number concentration BEL of 20,000 particles $/ \mathrm{cm}^{3}$, discriminated from the ambient environmental particle concentration. It was later adopted and developed by the Institute for Occupational Safety and Health of the German Social Accident Insurance (IFA DGUV) and the IVAM Environmental Research UVA BV from Netherlands (Schumacher and Pallapies 2009; van Broekhuizen et al. 2012). The relationship between number concentration and mass concentration for benchmark exposure levels has been examined by IFA. Average particle sizes and density variations were examined, and the number concentration corresponding to a mass concentration of $0.1 \mathrm{mg} / \mathrm{m}^{3}$ was calculated for several EMNs.

Safe levels were considered, by Dutch Social and Economic Council (SER, Sociaal-Economische Raad - an advisory body to the Dutch government and the parliament on national and international social and economic policy), nano reference values (NRVs). Generally:

- Fibre concentration for carbon nanotubes and metal oxide fibres should not exceed 0.01 fibre $/ \mathrm{cm}^{3}$,

- For particles with a density higher than $6 \mathrm{~g} / \mathrm{cm}^{3}$ (some metallic particles like $\mathrm{Ag}, \mathrm{Au}, \mathrm{Fe}, \mathrm{Pb}$ and metal oxides like $\mathrm{CoO}, \mathrm{CeO}_{2}, \mathrm{SnO}_{2}, \mathrm{Fe}_{\mathrm{x}} \mathrm{O}_{\mathrm{y}}$ ), the proposed threshold concentration for the introduction of appropriate exposure control measures is 20,000 particles $/ \mathrm{cm}^{3}$,

- For particles with a density lower than $6 \mathrm{~g} / \mathrm{cm}^{3} \mathrm{NRV}$ like metal oxides (e.g. $\mathrm{TiO}_{2}, \mathrm{ZnO}, \mathrm{Al}_{2} \mathrm{O}_{3}$ ), fullerenes, dendrimers, nanoclay, polystyrene, $\mathrm{SiO}_{2}$, carbon black, etc., NRV is 40,000 particles $/ \mathrm{cm}^{3}$.

These values have been established temporarily for the particles in the measured range between 1 and $100 \mathrm{~nm}$ and may change as knowledge of the toxicity of nanomaterials progresses. These safe levels were adopted as the reference values in this work.

Since nanoparticles are characterized by a highly developed surface area, geometric surface area of the particles should be also considered. Currently available real-time measuring instruments do not measure this parameter of nanoparticles; however, they can determine the lung deposited surface area (LDSA) or "active" surface area. The LDSA concentration is considered a relevant metric for the negative health effects of aerosol particles. It has been shown in toxicological studies that LDSA correlates with negative health effects (Brown et al. 2001; Geiss et al. 2016; Kuuluvainen et al. 2016; Oberdörster et al. 2005). LDSA is a metric that takes into account the deposition efficiency of airborne objects in different compartments of the lung. A deposition model was described and defined for a reference working person (ICRP 1994) (for more details on the amount of deposited particles in the human respiratory tract, see (ISO 2012a)).

Occupational exposure limits for ENM have been well reviewed by Mihalache et al. (Mihalache et al. 2017). 


\section{Task-based exposure assessment}

There are numerous nanoparticles and ultrafine particles present in our everyday environment. Their origin can be natural (e.g. desert dusts, ash, sea salt, viruses and bacterial remains, metal oxides), accidental (e.g. combustion exhaust, soot, products of technological processes), and from specially manufactured (engineered) nanomaterials. The presence of such background NOAA in workplace atmospheres is unavoidable and must be considered in task-based exposure assessment. The average background concentration of indoor nanoaerosols was reported by Seipenbusch et al. (Seipenbusch et al. 2008) in the range of 1000 to 10,000 particles $/ \mathrm{cm}^{3}$ in a clean interior. In reports of BSI, Project Scaffold and European Commission guidance, on the protection of the health and safety of workers from the potential risks related to nanomaterials at work, it was stated that urban air typically contains between 10,000 and 50,000 nanoparticles/ $\mathrm{cm}^{3}$ (BSI 2007; EC 2014; Helene Stockmann-Juvala and Santonen 2014).

A good solution, enabling the identification of the emission source during the working time, is real-time monitoring of NOAA concentration in the air focused on particular tasks and events. An approach proposed by ISO in the technical specification ISO/TS 12901-2:2014 (ISO 2014) is to reference the values recorded during a given task, process or activity to the background level concentration $\left(\mathrm{N}_{\mathrm{p}} / \mathrm{N}_{\mathrm{b}}\right)$. In this approach, the background level (average concentration recorded before or after the process) is the reference point. The first, lowest level of exposure relates to a ratio below 1.1, which means that the concentration value determined during the action with NOAA emission differs less than $10 \%$ from the background level and is not significant. The fourth, highest level of exposure corresponds to a ratio higher than 2, which means that the concentration recorded during the specific event is twice as high as the background level. Results of international measurements of nanomaterials at workplaces, based on this approach, were provided by Brouwer et al. (Brouwer et al. 2013). The method is also adopted in this work for task-based exposure assessment. Two additional standards EN 16966 and EN 17058 (CEN 2018a, b) can be useful as well for the purposes of exposure determination.

A standardized sampling strategy with a task-based approach guarantees that all collected data, documentation and context for the exposure measurement are harmonized and allows for comparisons among different exposure scenarios (Brouwer 2012; Brouwer et al. 2009; Ramachandran et al. 2011). Task-based exposure assessments are most significant for activities with a high degree of daily variability, typical for the nanotechnology industry, which utilizes batch processing more often than continuous mass production (Seixas et al. 2003).

Nano Exposure and Contextual Information Database

Exposure evaluation and risk management for NOAA requires knowledge about the specific material, such as biological and physico-chemical parameters, real-time monitoring and proper sampling for chemical and morphological (microscopic) characterization of nano-objects, as well as data on contextual information about the premises, workers and background.

The purposes of the research were to investigate the actual levels of exposure to nano-objects in real working conditions using a task-based approach and to gather harmonized data for European PEROSH Nano Exposure and Contextual Information Database-NECID (Oberbek 2018; Pelzer and Schumacher 2018). NECID is mentioned and described in Annex C to EN 17058 standard (CEN 2018a) as a template for contextual information for comprehensive assessment. As the document states, "field forms in line with the NECID database are the preferred means for the collection of data during exposure measurements".

This article presents the results of the measurements with contextual information on emission of nanoparticles at four workplaces, where different processes were carried out: synthesis of silver nanoparticles, generation of thin nanocarbon layers, 3D-printing with nanocomposites and the production of special seals from thin glass foils.

\section{Material and methods}

Measuring instruments

Aerosols at the workplaces were studied using online methods (real-time particle concentration counters) and offline methods (air sampling for gravimetric evaluation and electron microscopy analysis). 


\section{Real-time measurements}

Measuring devices for real-time monitoring of airborne nanoparticles differ in used methods, measuring range (max number of particles, diameter of particles), time interval, accuracy etc. For these measurements, three identical miniature diffusion size classifiers (DiSCmini, Testo-handheld nanoparticle counter) were chosen (Fierz et al. 2011). Their main advantages are as follows: low weight (670 g), small size, portability, and battery operation without the need for an additional power supply. DiSCmini work with aerosol flow rate of $1 \mathrm{dm}^{3} / \mathrm{min}$. The aerosol particles are electrically charged in a nonradioactive unipolar diffusion charger. Device measures the total particle number concentration, LDSA $\left(\mu \mathrm{m}^{2} / \mathrm{cm}^{3}\right)$ concentration and the mean particle diameters (assuming a log-normal particle size distribution). The instrument can detect particles with a mode diameter between 10 and $300 \mathrm{~nm}$ in a concentration range from $10^{3}$ to above $10^{6}$ particles $/ \mathrm{cm}^{3}$ with $\pm 30 \%$ accuracy (manufacturer information). Pre-impactor is cutting out aerosol particles sized above $\sim 700 \mathrm{~nm}$. Time interval is $1 \mathrm{~s}$ for a scan, but for better readability the results in this study are presented in a minute scale (average values from every $60 \mathrm{~s}$ ).

\section{Air sampling for microscopic analysis}

Airborne dust samples form scanning electron microscopy (SEM) analysis were collected using a personal air pump (Gilair Plus, Sensidyne) with a mini particle sampler (MPS, ECOMESURE) on TEM grids $(\mathrm{Cu}$ Quantifoil 1.2/1.3, 400 mesh) with Agar Grids $2000 \mu \mathrm{m}$ Hole Copper $3.05 \mathrm{~mm}$ gaskets. Aerosol flow rate of the sampling setup was $0.8 \mathrm{dm}^{3} / \mathrm{min}$.

\section{Scanning electron microscopy}

Morphological analysis of dust samples collected on TEM grids was conducted using a field emission scanning electron microscope (Hitachi SU8010). An accelerating voltage of $5-20 \mathrm{kV}$ was applied. Observations were conducted in $\mathrm{SE}(\mathrm{U})$ mode. Length (expressed by maximum linear diameter, $\mathrm{nm}$ ) of the nanoparticles was calculated from at least 50 objects from images magnified at least 50k times. Length of nanoparticle agglomerates and/or aggregates was estimated from at least 10 objects (only estimated because process of agglomeration and aggregation could occur during sampling).
Analyses were performed from representative SEM images using ImageJ software (Waseda and Muramatsu 2013). Basic point chemical analysis for the confirmation of the NOAA presence in the suspected sources has been carried out using the Thermo Scientific NORAN System 7 equipped with electrically cooled Silicon Drift Detector EDS detector (Thermo Scientific UltraDry). An X-ray microanalyzer (EDS, energy dispersion spectroscopy) was used to carry out basic chemical analysis and confirm the absence or presence of NOAA from the suspected source.

\section{Respirable dust fraction measurements}

Personal air pump (SG 10-2, GSA, Germany) with a dust sampling system (cyclone FSP 10, GSA, Germany) was used to collect the respirable dust fraction on cellulose filters for gravimetric analysis. The air flow rate during the sampling was $10 \mathrm{dm}^{3} / \mathrm{min}$. To determine mass concentration of the respirable dust fraction, the sampling filters have been weighed with a micro balance (UMX2, Mettler Toledo) before and after the sampling, with additional conditioning for at least $20 \mathrm{~h}$ in both cases.

Detailed chemical analysis of the collected dust, although it could provide relevant data, was not planned in the research. The analysis was limited to identification of elements by the EDS method to confirm a presence of the nanomaterial in work environment, in accordance with the measurement strategy recommended in the ISO standard (ISO 2012b).

\section{Environment conditions}

Ambient air temperature, air pressure, air flow speed and relative humidity were measured using a termohigrobarometer (LB-702B, LAB-EL).

\section{Measurement strategy}

Three DiSCmini classifiers were used during each study to measure number concentration of nano- and submicron particles (particles $/ \mathrm{cm}^{3}$ ). First DiSCmini (DM-A) was placed closest to the worker at the breathing zone, second DiSCmini (DM-B) was placed as close as possible to suspected main NOAA source $(0.5-1 \mathrm{~m}$ from the main process) and third DiSCmini (DM-C) was used as additional reference and for checking possible secondary sources. In same spots, measurements of 
background NOAA concentration (as a reference for further results) were executed. Background level was recorded with the same DiSCmini classifiers at least $1 \mathrm{~h}$ before the work process was started. The same time was set on every measuring device.

At least two samples for SEM/EDS analysis were collected during the chosen activities, using MPS samplers. The sampling time was about $20 \mathrm{~min}$ for each sample.

Air samples for gravimetric analysis were collected during the whole shift. The respirable fraction (the mass fraction of inhaled particles penetrating to the respiratory region) was checked as a supplementary measure. Although concentration of this fraction does not facilitate the evaluation of exposure to single nanoparticles, it is very important due to the potential occurrence of large micro agglomerates and/or aggregates of nanoparticles.

During sampling, the researcher recorded information about the premises, environment conditions, ventilation, local safety control and the process itself. The worker activities were described in detail with exact time of their execution. Contextual information was later matched with the concentration profiles received from real-time monitoring devices. Obtained data from each study was later entered into the NECID database.

Workplaces and studied processes

Four workplaces (WP) situated in Polish companies with small-scale manufacturing participated in this study. Description of each workplace and studied processes are below.

WP1-chemical laboratory where special seals from thin glass foils were manufactured by one worker from a powder containing silica, boron and aluminium compounds (boron-aluminium silicate glass)

The worker performed several activities related to the production of seals: weighing reagents, pouring into the crucible mixing ingredients, operating laser cutting tool, manually cleaning the seals with brush (removing scorched pieces), spraying with silicone. It was suspected that mixture of ultrafine particles, especially $\mathrm{SiO}_{2}$, could be incidentally emitted during the laser cutting of boron-aluminium silicate glass. Two hundred grams of powder (powder in standard grain size $\mathrm{d}_{50} \leq$ $10 \mu \mathrm{m}$, density $3.7 \mathrm{~g} / \mathrm{cm}^{3}$ ) was used to prepare glass foil.
DM-A was placed close to the glass foil synthesis sit (place closest to the worker); DM-B was placed close to the protective chamber of the laser cutting machine. DM-C was used as a control and a mobile meter for checking possible additional sources of emission.

The background level was recorded at each position/ instrument $1 \mathrm{~h}$ before the start of the work. Activities were recorded for $3.5 \mathrm{~h}$. The worker wore a lab coat and disposable gloves. No other personal protective equipment (PPE) was worn.

The laboratory was located in an old building, in a room with poor general ventilation. Building was located in industrial area (about $200 \mathrm{~m}$ to the nearest industrial installation).

The cubature of the studied room was $51 \mathrm{~m}^{3}$. One worker was involved in a process. Studies were conducted in the winter, at the end of 2017. An outline drawing of the workplace, without maintaining the exact proportions of the room, has been presented in Fig. 1.

\section{WP2 - a new research and development laboratory where thin nanocarbon layers were generated in electric arc from carbon electrodes}

The worker performed only the activities related to the process: turning on, cleaning, changing the electrode, operating the software, monitoring and shutting down the process. The whole process was carried out in a closed chamber. About $5 \mathrm{mg}$ of electrode was burned in the process. Average particle size declared by a worker was about $50-150 \mathrm{~nm}$.

DM-A was recording outside the chamber, close to the worker, and DM-B was placed inside the chamber. DM-C was used as a control and a mobile meter for checking possible additional sources of emission.

The background level was recorded $1 \mathrm{~h}$ before the start of the work. The activities were recorded for about $5 \mathrm{~h}$. The worker wore a lab coat and disposable gloves. No other personal protective equipment (PPE) was worn.

The laboratory was located in a new facility with efficient hybrid ventilation. Facility was located close to the main road with high traffic (about 80-m distance).

The cubature of the studied room was $166 \mathrm{~m}^{3}$. Two workers were involved in a process. Studies were conducted in July 2018. An outline drawing of the workplace, without maintaining the exact proportions of the room, has been presented in Fig. 2. 


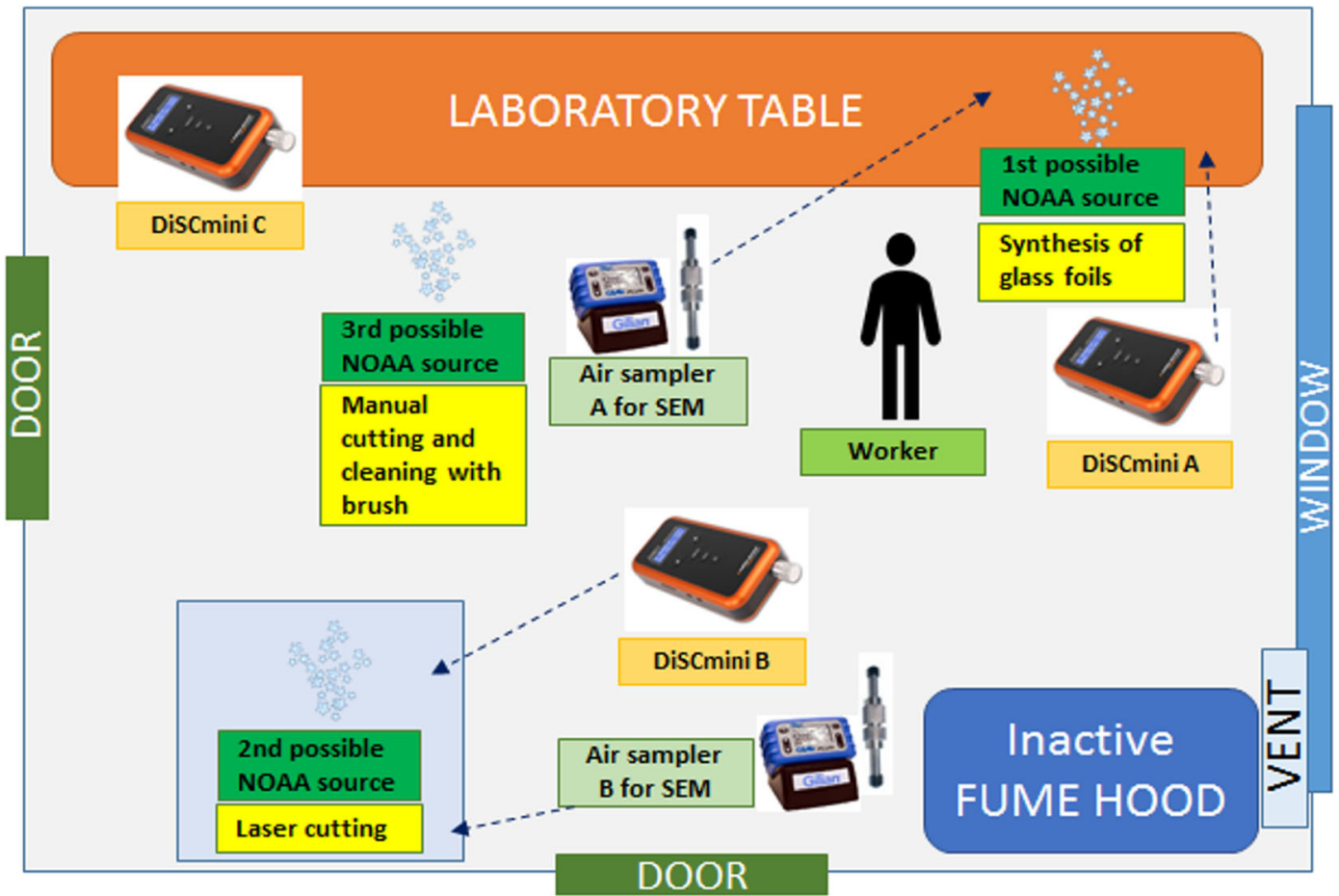

Fig. 1 Outline drawing of WP1

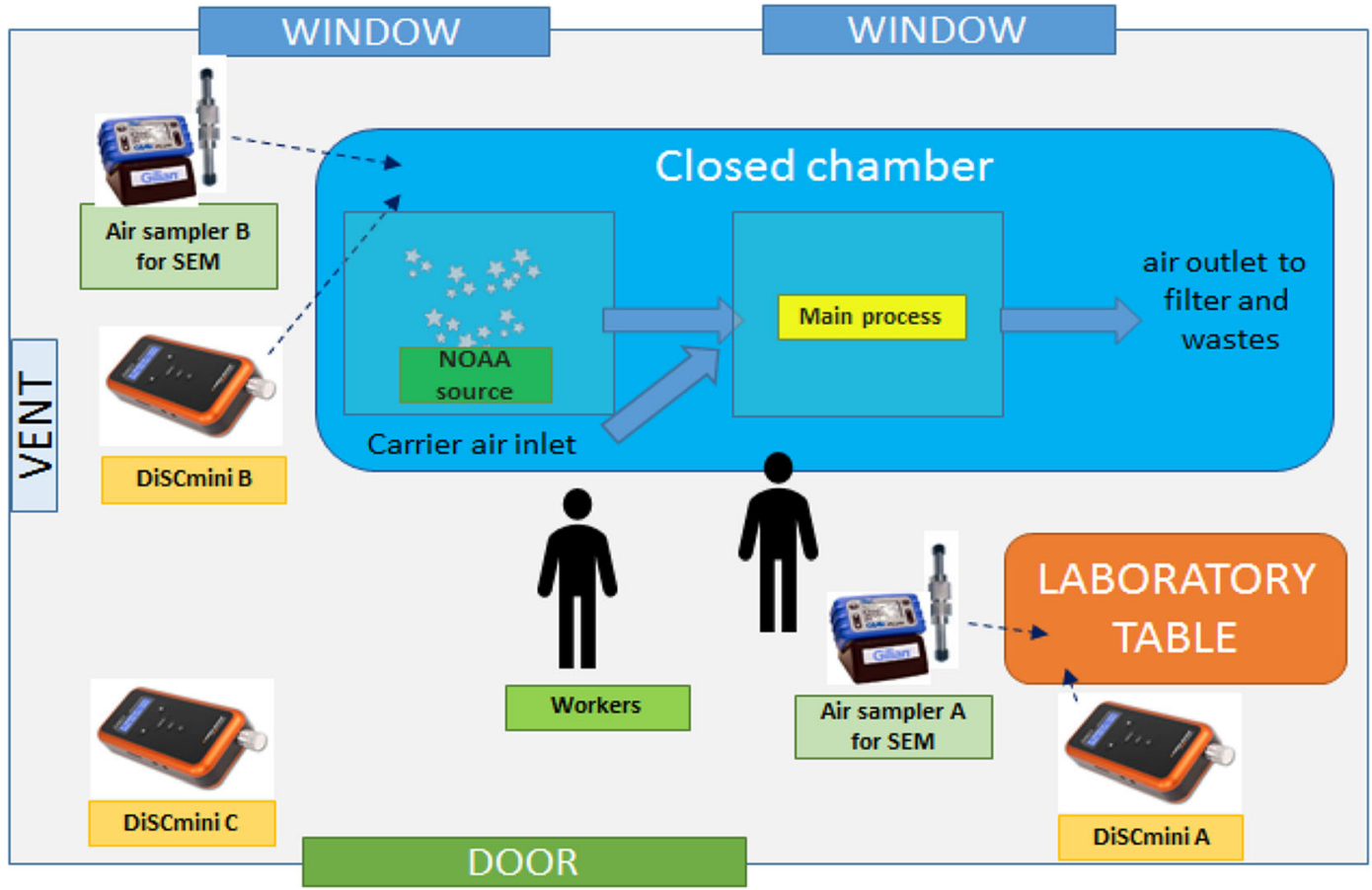

Fig. 2 Outline drawing of WP2 
WP3 - a clean, new laboratory where $3 D$-printing (rapid prototyping) with the use

of nanohydroxyapatite-polymer composites was carried out (additive manufacturing of nanocomposite

implants)

The worker performed several activities related to the manufacturing: turning on the 3D-printer, backfilling nanocomposite granulate, operating a software, monitoring the process, checking other devices, shutting down, cleaning. It has been suspected that thermal processing of the nanocomposite during the 3D-printing process might cause incidental emission of NOAA. The whole process was carried out in a half-closed protective chamber. Nanocomposite contained $50 \%$ of nanohydroxyapatite in polymer matrix. Nine grams of nanopowder was used for the preparation of printer filament (average particle size declared by the manufacturer was $32 \mathrm{~nm}$, density $2.9 \mathrm{~g} / \mathrm{cm}^{3}$ ).

DM-A was placed close to the worker, outside the protective chamber of the 3D-printer, and DM-B was placed inside the chamber. DM-C was used as a control and a mobile meter for checking possible additional sources of emission.

The background level was recorded $1 \mathrm{~h}$ before the start of work. Activities were recorded for about $4.5 \mathrm{~h}$. The worker wore protective goggles, a lab coat and disposable gloves. No other personal protective equipment (PPE) was worn.

The laboratory was in a new, clean facility with efficient mechanical ventilation. Facility was located in secluded area.

Laboratory room did not have access to the windows and was surrounded by other rooms and a corridor. The cubature of the room was $65 \mathrm{~m}^{3}$. One worker was involved in a main process; two other workers were conducting other tasks in same room but only occasionally. Studies were conducted in August 2018. An outline drawing of the workplace, without maintaining the exact proportions of the room, has been presented in Fig. 3.

\section{WP4- a small, new laboratory equipped with a fume hood, indoor area belonging to a private company, where silver nanoparticles are chemically synthesised}

The worker performed several activities related to the synthesis: preparation of reagents, weighing, preparing the setup inside the fume hood, monitoring the process, ending the synthesis, pouring the suspension into a vessel, cleaning. It has been suspected that the mixing of reagents could cause the incidental emission of silver nanoparticles. The whole mixing process was carried out under the working fume hood. Two hundred milligrams of nanosilver colloid was prepared in a solution (average particle size declared by a worker was about $50 \mathrm{~nm})$.

DM-A was placed at the laboratory table where reagents were prepared, close to the worker, and DM-B was placed inside the fume hood where synthesis was conducted. DM-C was used as a control and a mobile meter for checking possible additional sources of emission.

The background level was recorded $1 \mathrm{~h}$ before the start of work. Activities were recorded for about $2 \mathrm{~h}$. The worker wore protective goggles, disposable gloves and a lab coat. No other personal protective equipment (PPE) was worn.

The laboratory belongs to a private company and was located in a new, clean room and was a part of a larger facility. Facility was located close to the inner alley with a little traffic (about $60 \mathrm{~m}$ ) and close to the main, hightraffic railway route (about $100 \mathrm{~m}$ ). In the close vicinity there were buildings of small industrial companies (about 20 and $50 \mathrm{~m}$ ). There was a large construction work nearby (about $250 \mathrm{~m}$ ).

General ventilation in laboratory was functioning during the measurements. The cubature of the room was $48 \mathrm{~m}^{3}$, and the studies were conducted in October 2018. An outline drawing of the workplace, without maintaining the exact proportions of the room, has been presented in Fig. 4.

\section{Results}

Results of real-time measuring with devices DM-A and DM-B for each workplace (WP1 to WP4) are presented in Figs. 5, 6, 7, and 8. Significant peaks from the DM-C results coincided with the peaks of DM-A and DM-B, but due to its distance from the source, their value was lower. For the sake of simplicity, the graphs from DM-C are not shown.

Times, tasks and important events, concentration recorded during a given task, process/activity concentration over the given time interval $\left(\mathrm{N}_{\mathrm{p}}\right)$ to the concentration of background level $\left(\mathrm{N}_{\mathrm{b}}\right)$, and alveolar lung deposited surface area (LDSA) are described in Tables 1, 2, 3, and 4 . Peaks are described under the tables. 


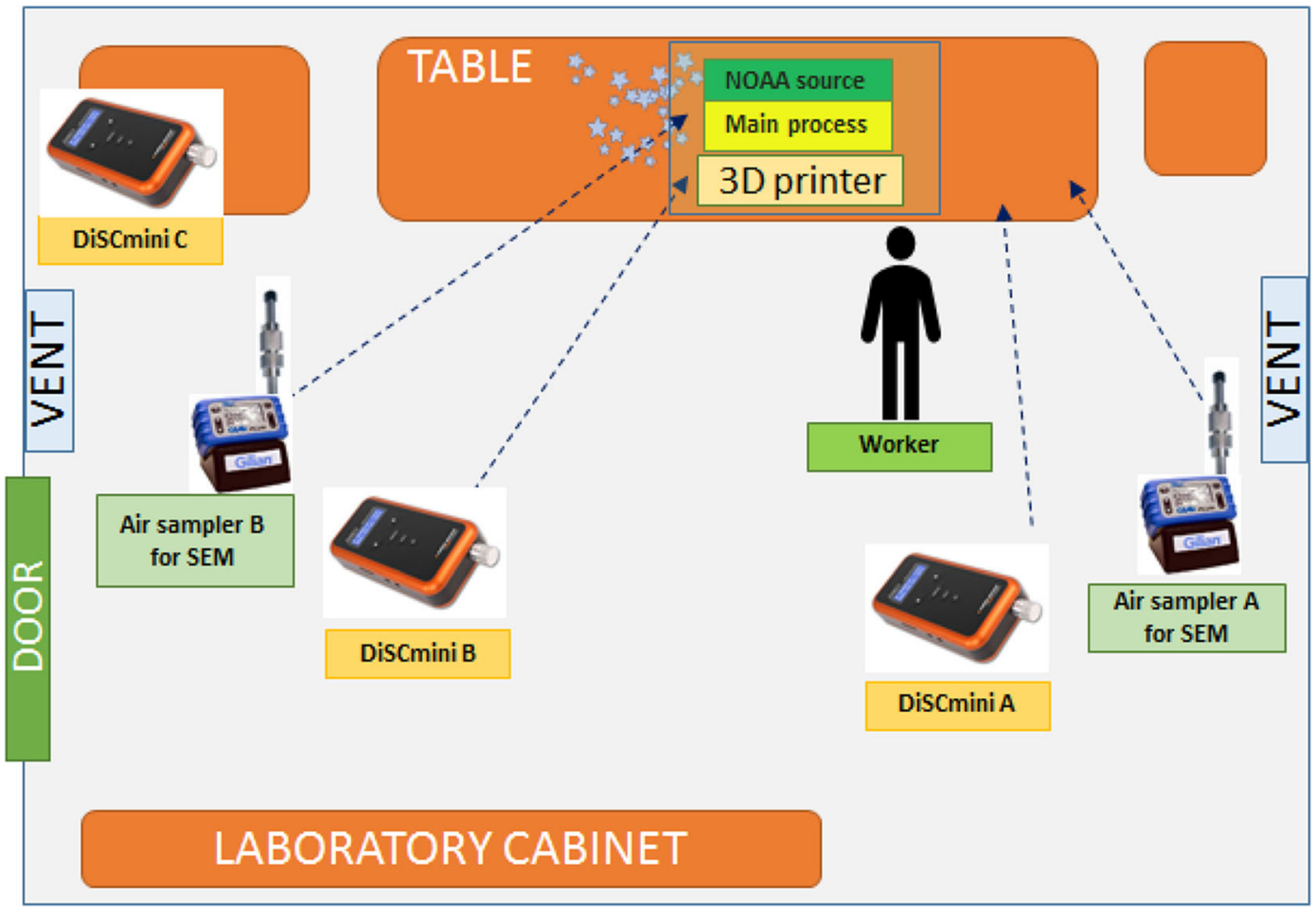

Fig. 3 Outline drawing of WP3

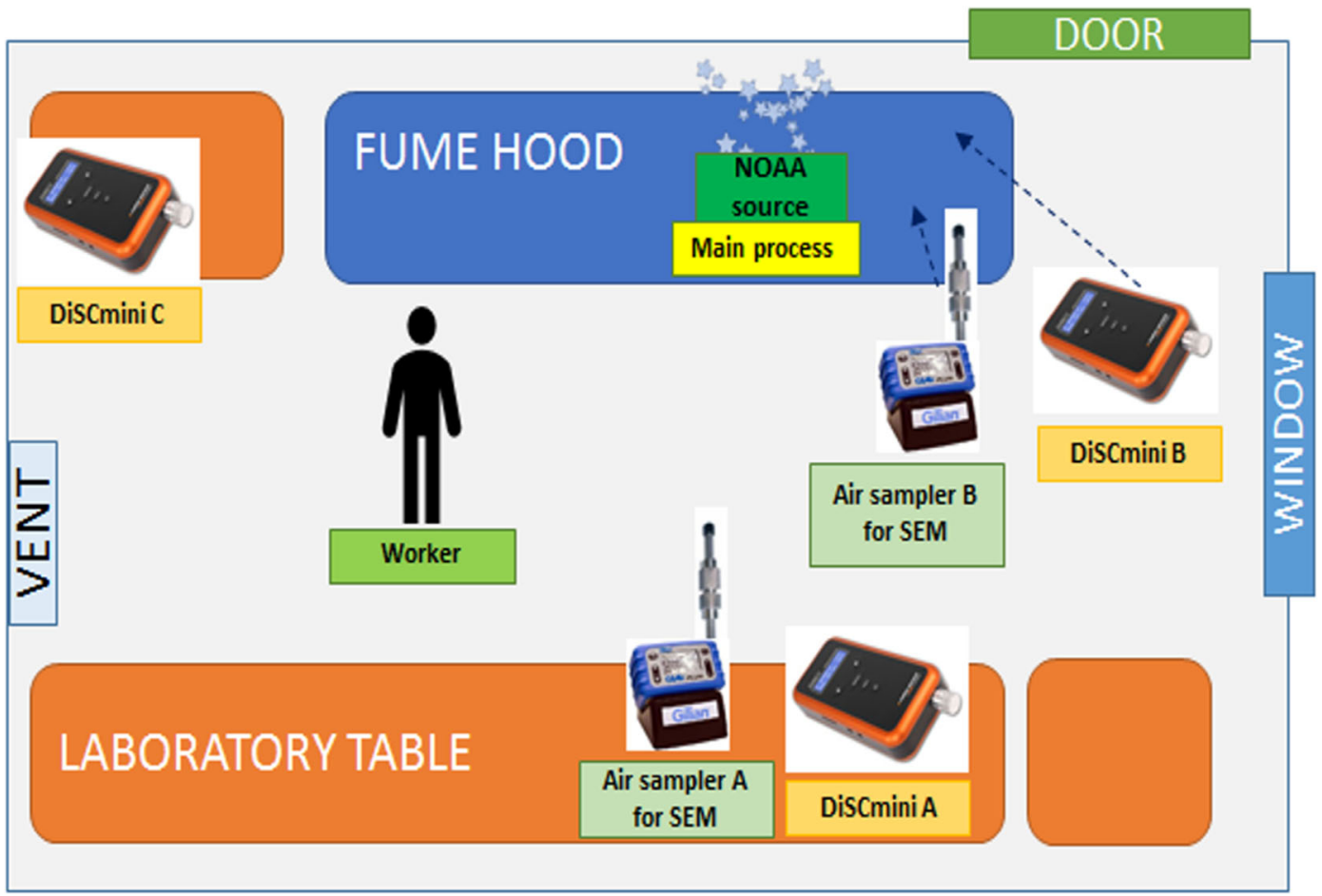

Fig. 4 Outline drawing of WP4 


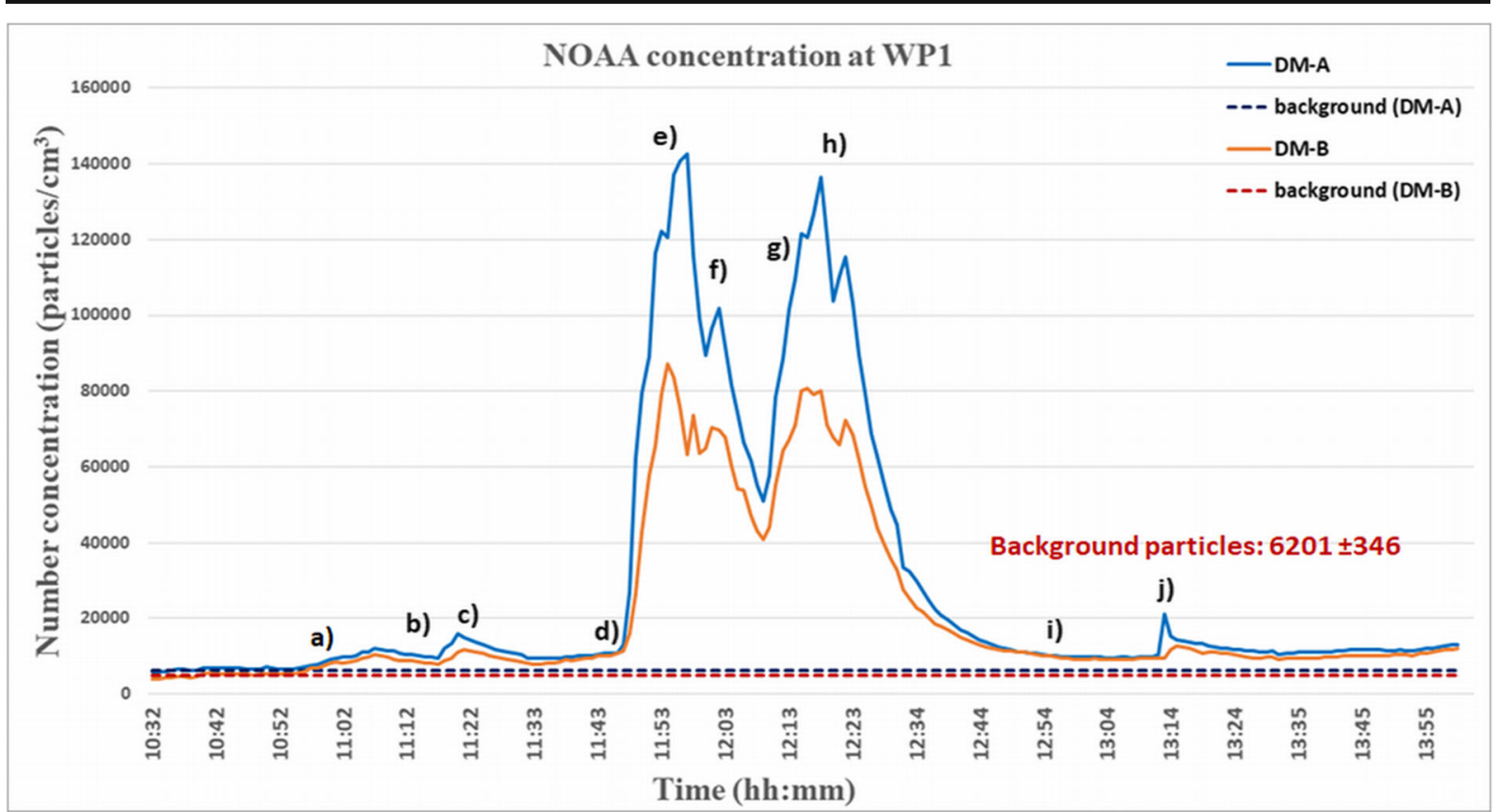

Fig. 5 Results of the real-time measurements at WP1 of NOAA by time and number concentration during the process-laser cutting of boron-aluminium silicate glass; DM-A (blue line) was placed close to the glass foils synthesis site, where the worker spent most of the time; DM-B (orange line) was placed near the protective chamber of the laser cutting machine

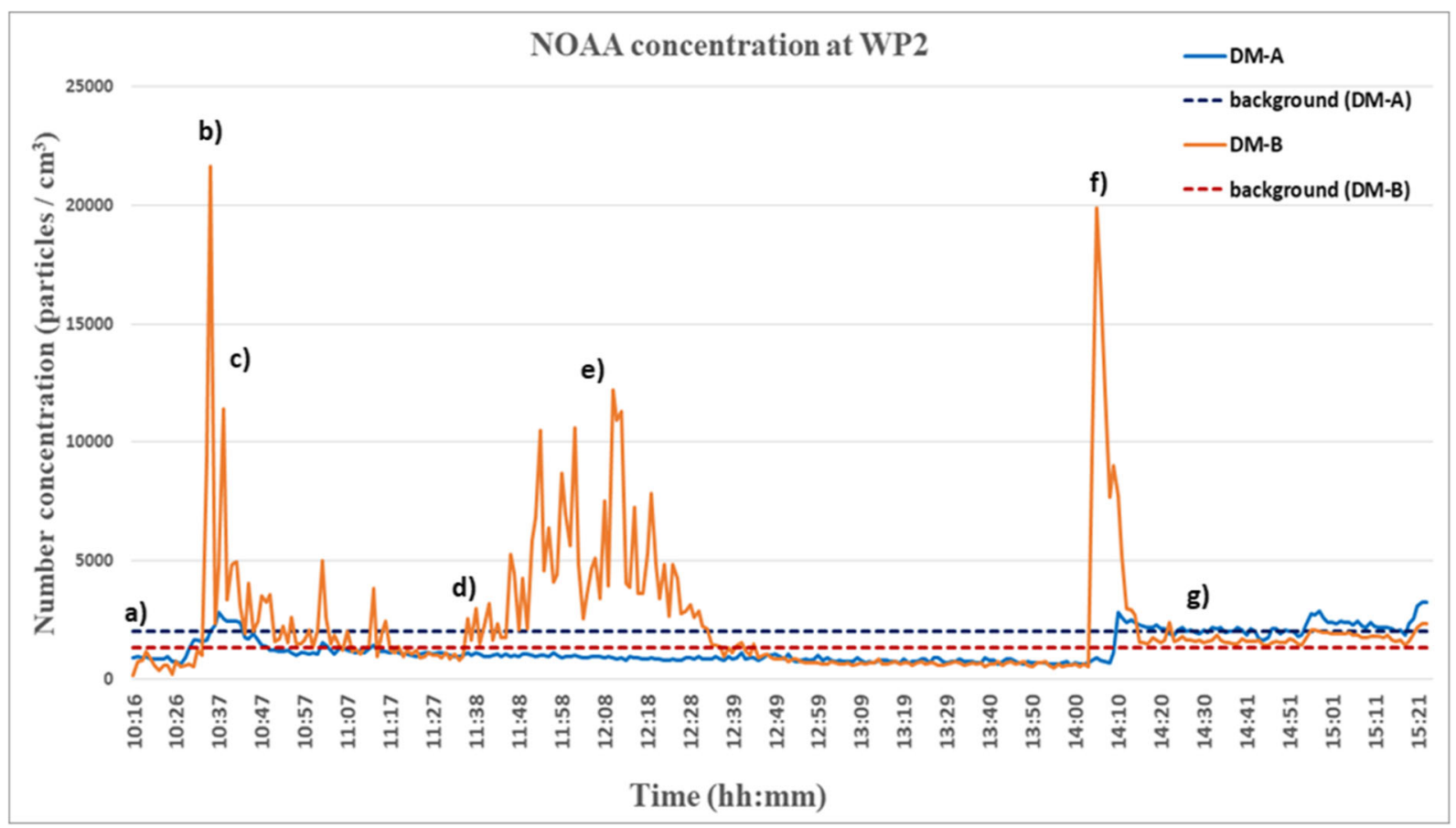

Fig. 6 Results of the real-time measurements at WP2 of NOAA by time and number concentration during the process - generation of thin nanocarbon layers; DM-A (blue line) was recording outside the chamber, close to the worker; DM-B (orange line) was placed inside the chamber 


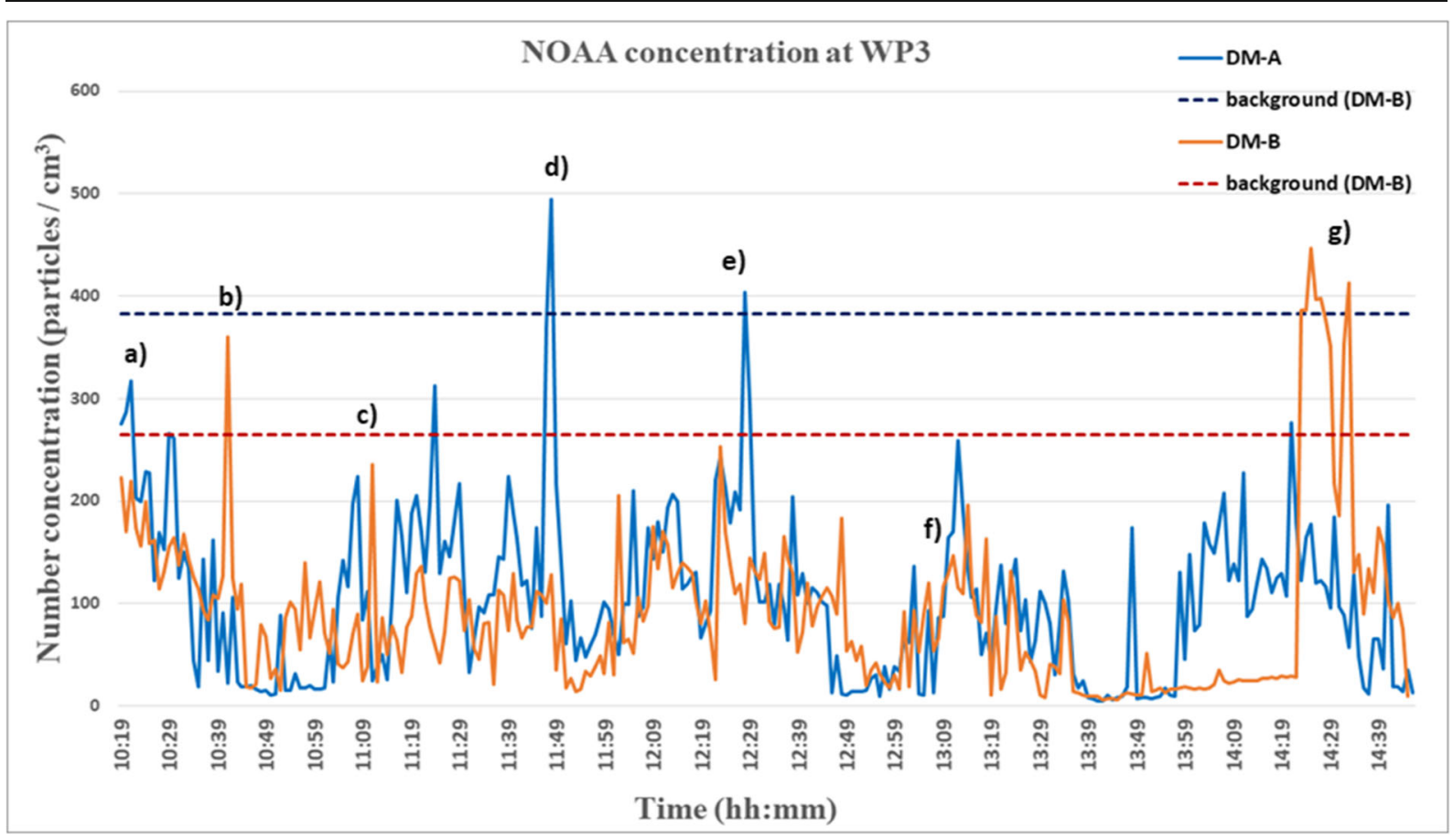

Fig. 7 Results of the real-time measurements at WP2 of NOAA by time and number concentration during the process - 3D-printing with a composite containing nanohydroxyapatite; DM-A (blue line) was placed close to the worker, outside the protective chamber of the 3D-printer; DM-B (orange line) was placed inside the chamber

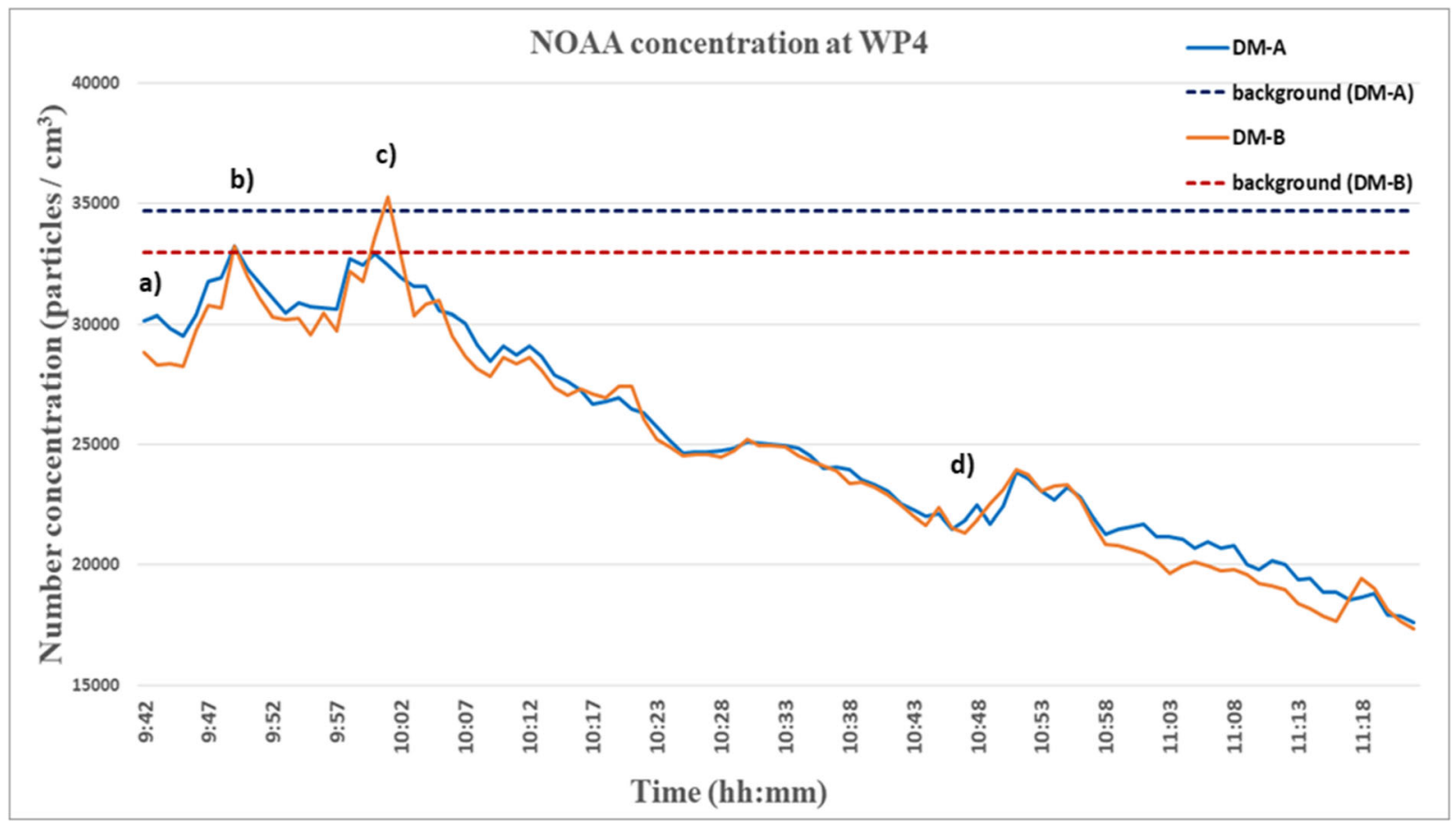

Fig. 8 Results of the real-time measurements at WP2 of NOAA by time and number concentration during the process - chemical synthesis of silver nanoparticles; DM-A (blue line) was placed at the laboratory table where reagents were prepared, close to the worker; DM-B (orange line) was placed inside the fume hood where synthesis was conducted 
Table 1 Summary statistics by important tasks and events in WP1 (main process: laser cutting of boron-aluminium silicate glass); DM-A was placed closest to the worker, and DM-B was placed as close as possible to suspected ultrafine particles source

\begin{tabular}{|c|c|c|c|c|c|c|c|}
\hline $\begin{array}{l}\text { Task/ } \\
\text { event }\end{array}$ & Time (min) & $\begin{array}{l}\text { DM-A average number } \\
\text { concentration during the } \\
\text { task (particles } / \mathrm{cm}^{3} \text { ) }\end{array}$ & $\begin{array}{l}\mathrm{DM}- \\
\mathrm{A} \\
\mathrm{N}_{\mathrm{p}} / \\
\mathrm{N}_{\mathrm{b}}\end{array}$ & $\begin{array}{l}\text { DM-A average } \\
\text { LDSA during the } \\
\text { task }\left(\mu \mathrm{m}^{2} / \mathrm{cm}^{3}\right)\end{array}$ & $\begin{array}{l}\text { DM-B average number } \\
\text { concentration during the } \\
\text { task (particles } / \mathrm{cm}^{3} \text { ) }\end{array}$ & $\begin{array}{l}\mathrm{DM}- \\
\mathrm{B} \mathrm{N}_{\mathrm{p}} / \\
\mathrm{N}_{\mathrm{b}}\end{array}$ & $\begin{array}{l}\text { DM-B average } \\
\text { LDSA during the } \\
\text { task }\left(\mu \mathrm{m}^{2} / \mathrm{cm}^{3}\right)\end{array}$ \\
\hline a) & 10:58-11:09 & 10,158 & 1.64 & 24.42 & 8728 & 1.75 & 24.26 \\
\hline b) & $11: 14-11: 18$ & 10,171 & 1.64 & 25.06 & 8195 & 1.65 & 22.88 \\
\hline c) & $11: 19-11: 23$ & 14,420 & 2.33 & 38.75 & 10,881 & 2.19 & 33.51 \\
\hline d) & $11: 45-11: 48$ & 15,372 & 2.48 & 38.54 & 11,970 & 2.40 & 24.57 \\
\hline e) & $11: 49-11: 56$ & 108,563 & 17.51 & 399.47 & 64,827 & 13.02 & 262.38 \\
\hline f) & $12: 00-12: 04$ & 92,301 & 14.88 & 328.74 & 66,602 & 13.37 & 305.33 \\
\hline g) & $12: 09-12: 13$ & 75,385 & 12.16 & 257.50 & 54,251 & 10.89 & 223.40 \\
\hline h) & $12: 07-12: 45$ & 63,548 & 10.25 & 232.79 & 43,957 & 8.83 & 205.64 \\
\hline i) & $12: 46-13: 10$ & 10,346 & 1.67 & 26.52 & 9947 & 2.00 & 24.27 \\
\hline j) & $13: 12-13: 15$ & 15,201 & 2.45 & 41.22 & 10,819 & 2.17 & 26.73 \\
\hline
\end{tabular}

Tasks, processes and important events: (a) beginning of the work; weighing reagents, pouring into the crucible, mixing ingredients; (b) 1st laser cutting of glass foils; (c) 2nd laser cutting of glass foils; (d) 3rd laser cutting of glass foils; (e) manual cleaning with brush, removing scorched pieces; (f) 4th laser cutting of glass foils; (g) 5th laser cutting of glass foils; (h) additional manual cutting and cleaning with brush; (i) turning off the laser cutting machine, turning on the vacuum pump, preparing for the next day's processes; (j) spraying the silicone

Modal minimal and maximal sizes of particles (average size) were $51.1 \pm 9.5 \mathrm{~nm}$ for DM-A (size ranged from 36.9 to $72.8 \mathrm{~nm}$ ) and $57.9 \pm$ $16.5 \mathrm{~nm}$ for DM-B (size ranged from 37.3 to $103.6 \mathrm{~nm}$ )

Results obtained with DiSCmini devices at WP1

Recorded background level (particles $/ \mathrm{cm}^{3}$ ) was $6201 \pm 346$ for DM-A and $4980 \pm 398$ for DM-B.
The magnitude of the standard deviation from the average value of the background nanoparticle concentration indicates small background fluctuation.

Table 2 Summary statistics by important tasks and events in WP2 (main process: generation of a thin nanocarbon layers); DM-A was placed closest to the worker, and DM-B was placed as close as possible to the suspected NOAA source

\begin{tabular}{|c|c|c|c|c|c|c|c|}
\hline $\begin{array}{l}\text { Task/ } \\
\text { event }\end{array}$ & Time (min) & $\begin{array}{l}\text { DM-A average number } \\
\text { concentration during the } \\
\text { task/event (particles } / \mathrm{cm}^{3} \text { ) }\end{array}$ & $\begin{array}{l}\mathrm{DM}- \\
\mathrm{A} \\
\mathrm{N}_{\mathrm{p}} / \\
\mathrm{N}_{\mathrm{b}}\end{array}$ & $\begin{array}{l}\text { DM-A average } \\
\text { LDSA during the } \\
\text { task }\left(\mu \mathrm{m}^{2} / \mathrm{cm}^{3}\right)\end{array}$ & $\begin{array}{l}\text { DM-B average number } \\
\text { concentration during the } \\
\text { task/event (particles } / \mathrm{cm}^{3} \text { ) }\end{array}$ & $\begin{array}{l}\text { DM- } \\
\mathrm{B} \mathrm{N}_{\mathrm{p}} / \\
\mathrm{N}_{\mathrm{b}}\end{array}$ & $\begin{array}{l}\text { DM-B average } \\
\text { LDSA during the } \\
\text { task }\left(\mu \mathrm{m}^{2} / \mathrm{cm}^{3}\right)\end{array}$ \\
\hline a) & $10: 16-10: 20$ & 944 & 0.46 & 3.01 & 752 & 0.56 & 2.71 \\
\hline b) & $10: 25-10: 37$ & 1510 & 0.74 & 4.94 & 3643 & 2.73 & 9.33 \\
\hline c) & $10: 39$ & 2481 & 1.22 & 7.58 & 4978 & 3.74 & 17.02 \\
\hline d) & $11: 40-11: 43$ & 1001 & 0.49 & 3.62 & 2391 & 1.79 & 6.96 \\
\hline e) & $12: 05$ & 954 & 0.47 & 3.36 & 4682 & 3.51 & 11.79 \\
\hline f) & $14: 05$ & 910 & 0.45 & 3.67 & 19,868 & 14.91 & 45.70 \\
\hline g) & $14: 28$ & 1995 & 0.98 & 6.46 & 1613 & 1.21 & 5.36 \\
\hline
\end{tabular}

Tasks, processes and important events: (a) starting the generator; (b) cleaning the generator, changing electrodes; (c) starting of the main process; (d) two workers entered the room to check installation; (e) high activity during the process inside protective chamber; (f) small emission from the chamber; $(\mathrm{g})$ ending of the processes

Modal minimal and maximal sizes of particles (average size) were $64.6 \pm 14.3 \mathrm{~nm}$ for DM-A (size ranged from 44.2 to $88.8 \mathrm{~nm}$ ) and $65.3 \pm$ $6.3 \mathrm{~nm}$ for DM-B (size ranged from 38.8 to $210.3 \mathrm{~nm}$ ) 
Table 3 Summary statistics by important tasks and events in WP3 (main process: 3D-printing with a composite containing nanohydroxyapatite); DM-A was placed closest to the worker, and DM-B was placed as close as possible to suspected NOAA source

\begin{tabular}{|c|c|c|c|c|c|c|c|}
\hline $\begin{array}{l}\text { Task/ } \\
\text { event }\end{array}$ & Time (min) & $\begin{array}{l}\text { DM-A average number } \\
\text { concentration during the } \\
\text { task/event (particles } / \mathrm{cm}^{3} \text { ) }\end{array}$ & $\begin{array}{l}\mathrm{DM}- \\
\mathrm{A} \\
\mathrm{N}_{\mathrm{p}} / \\
\mathrm{N}_{\mathrm{b}}\end{array}$ & $\begin{array}{l}\text { DM-A average } \\
\text { LDSA during the } \\
\text { task }\left(\mu \mathrm{m}^{2} / \mathrm{cm}^{3}\right)\end{array}$ & $\begin{array}{l}\text { DM-B average number } \\
\text { concentration during the } \\
\text { task/event (particles } / \mathrm{cm}^{3} \text { ) }\end{array}$ & $\begin{array}{l}\mathrm{DM}- \\
\mathrm{B} \\
\mathrm{N}_{\mathrm{p}} / \\
\mathrm{N}_{\mathrm{b}}\end{array}$ & $\begin{array}{l}\text { DM-B average } \\
\text { LDSA during the } \\
\text { task }\left(\mu \mathrm{m}^{2} / \mathrm{cm}^{3}\right)\end{array}$ \\
\hline a) & $10: 19$ & 275 & 0.72 & 0.82 & 223 & 0.84 & 0.64 \\
\hline b) & $10: 40$ & 91 & 0.24 & 0.44 & 127 & 0.48 & 0.38 \\
\hline c) & $11: 00-11: 25$ & 122 & 0.32 & 0.44 & 76 & 0.29 & 0.34 \\
\hline d) & $11: 48$ & 495 & 1.29 & 0.57 & 128 & 0.48 & 0.34 \\
\hline e) & $12: 28$ & 404 & 1.06 & 0.62 & 80 & 0.30 & 0.34 \\
\hline f) & $13: 00-13: 20$ & 95 & 0.25 & 0.27 & 94 & 0.35 & 0.28 \\
\hline g) & $14: 15-14: 40$ & 113 & 0.29 & 0.32 & 195 & 0.74 & 0.26 \\
\hline
\end{tabular}

Tasks, processes and important events: (a) turning on the 3D-printer; (b) backfilling nanocomposite granulate, beginning of the processes; (c) two workers moving around the room; (d) unidentified activity during the process; (e) unidentified activity during the process; (f) one worker checking devices; $(\mathrm{g})$ ending the main process, turning off instruments, three workers in the room

Average sizes of particles were not calculated by DiSCmini devices due to a small concentration of recorded nano-objects

Results obtained with DiSCmini devices at WP2

Recorded background level (particles $/ \mathrm{cm}^{3}$ ) was $2036 \pm$ 1029 for DM-A and $1332 \pm 783$ for DM-B. The magnitude of the standard deviation from the average value of the background nanoparticle concentration indicates a medium size of the background fluctuation.

Results obtained with DiSCmini devices at WP3

Recorded background level (particles $/ \mathrm{cm}^{3}$ ) was $383 \pm$ 129 for DM-A and $264 \pm 97$ for DM-B. The magnitude of the standard deviation from the average value of the background nanoparticle concentration indicates a small size of the background fluctuation.

\section{Results obtained with DiSCmini devices at WP4}

Recorded background level (particles $/ \mathrm{cm}^{3}$ ) was 34,701 \pm 2756 for DM-A and $32,995 \pm 2876$ for DM-B. The magnitude of the standard deviation from the average value of the background nanoparticle concentration indicates a medium size of the background fluctuation.

\section{Results of SEM analysis}

Example of SEM micrographs with EDS analysis for each workplace (WP1 to WP4) are presented in Figs. 9, 10,11 , and 12 . Numerical results of image analysis are presented in Table 5.

Table 4 Summary statistics by important tasks and events in WP4 (main process: chemical synthesis of silver nanoparticles); DM-A was placed closest to the worker, and DM-B was placed as close as possible to suspected NOAA source

\begin{tabular}{|c|c|c|c|c|c|c|c|}
\hline $\begin{array}{l}\text { Task/ } \\
\text { event }\end{array}$ & $\begin{array}{l}\text { Time } \\
(\min )\end{array}$ & $\begin{array}{l}\text { DM-A average number } \\
\text { concentration during the } \\
\text { task/event (particles } / \mathrm{cm}^{3} \text { ) }\end{array}$ & $\begin{array}{l}\text { DM- } \\
\text { A } \\
\mathrm{N}_{\mathrm{p}} / \\
\mathrm{N}_{\mathrm{b}}\end{array}$ & $\begin{array}{l}\text { DM-A average } \\
\text { LDSA during the } \\
\text { task }\left(\mu \mathrm{m}^{2} / \mathrm{cm}^{3}\right)\end{array}$ & $\begin{array}{l}\text { DM-B average number } \\
\text { concentration during the } \\
\text { task/event (particles/ } \mathrm{cm}^{3} \text { ) }\end{array}$ & $\begin{array}{l}\mathrm{DM}- \\
\mathrm{B} \\
\mathrm{N}_{\mathrm{p}} / \\
\mathrm{N}_{\mathrm{b}}\end{array}$ & $\begin{array}{l}\text { DM-B average } \\
\text { LDSA during the } \\
\text { task }\left(\mu \mathrm{m}^{2} / \mathrm{cm}^{3}\right)\end{array}$ \\
\hline a) & 09:42 & 30,167 & 0.87 & 112.94 & 28,812 & 0.87 & 121.59 \\
\hline b) & 09:48 & 31,917 & 0.92 & 117.23 & 30,664 & 0.93 & 120.73 \\
\hline c) & $10: 00$ & 32,930 & 0.95 & 115.71 & 33,626 & 1.02 & 121.02 \\
\hline d) & $10: 47$ & 21,857 & 0.63 & 82.81 & 21,318 & 0.65 & 121.02 \\
\hline
\end{tabular}

Task and important events: (a) preparation of reagents; (b) beginning of the processes, mixing the reagents; (c) change of the solution colour to yellow - precipitation; (d) end of the synthesis, pouring the suspension into a vessel, shutting down the fume hood

Modal minimal and maximal sizes of particles (average size) were $69.7 \pm 1.5 \mathrm{~nm}$ for DM-A (size ranged from 66.2 to 72.7 ) and $76.0 \pm$ $2.0 \mathrm{~nm}$ for DM-B (size ranged from 70.2 to $80.8 \mathrm{~nm}$ ) 

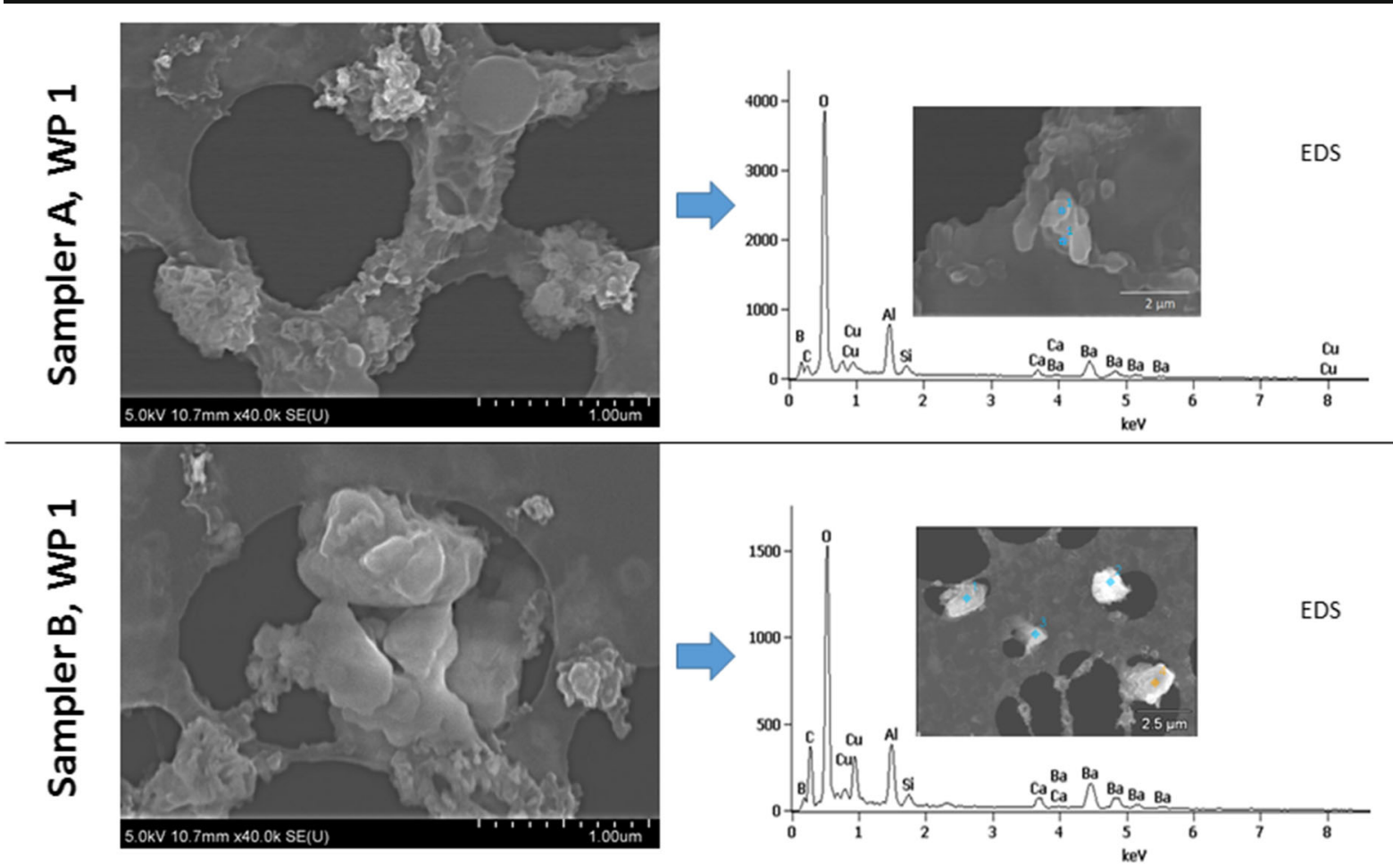

Fig. 9 SEM images and EDS analysis of samples collected at WP1
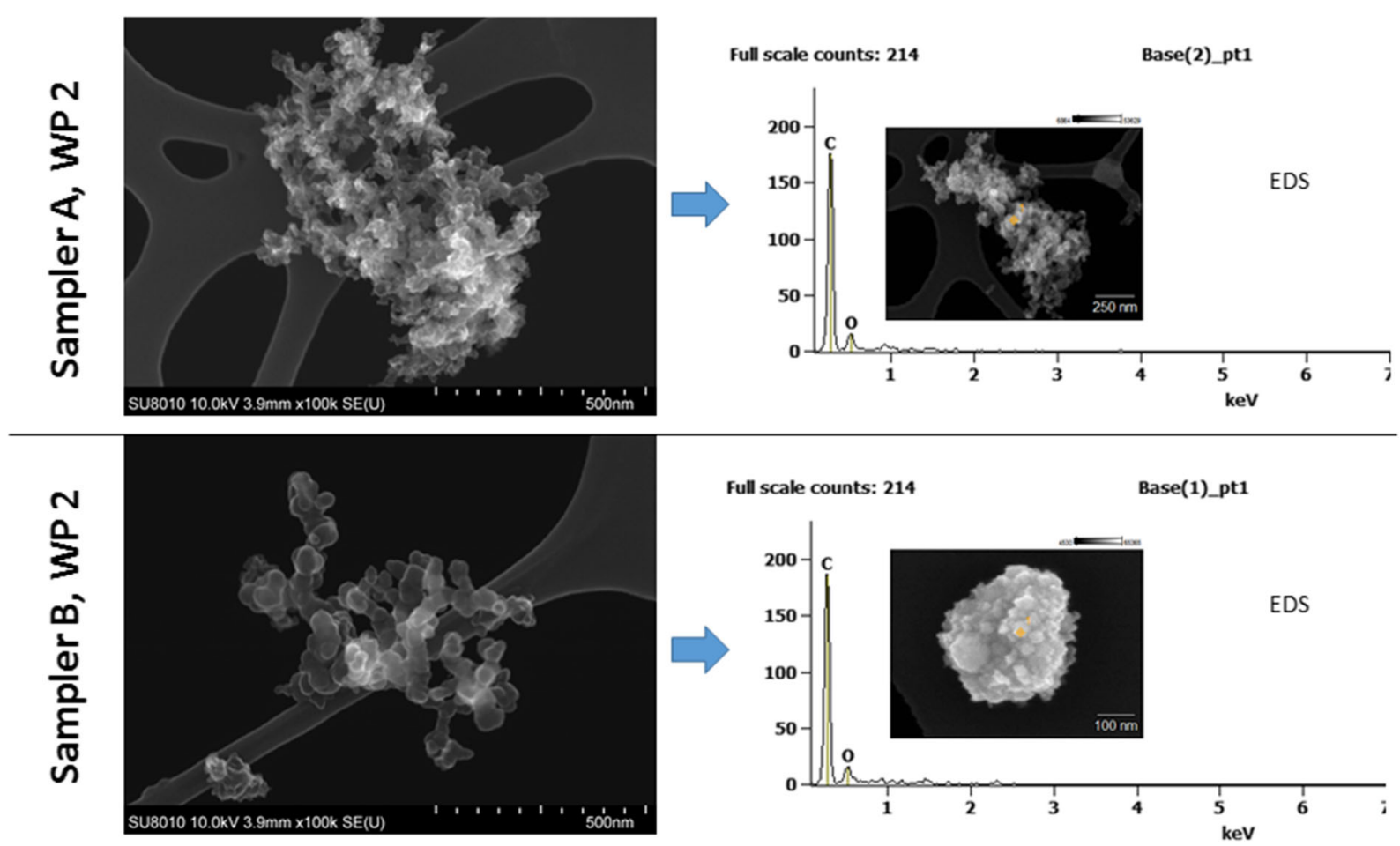

Fig. 10 SEM images and EDS analysis of samples collected at WP2

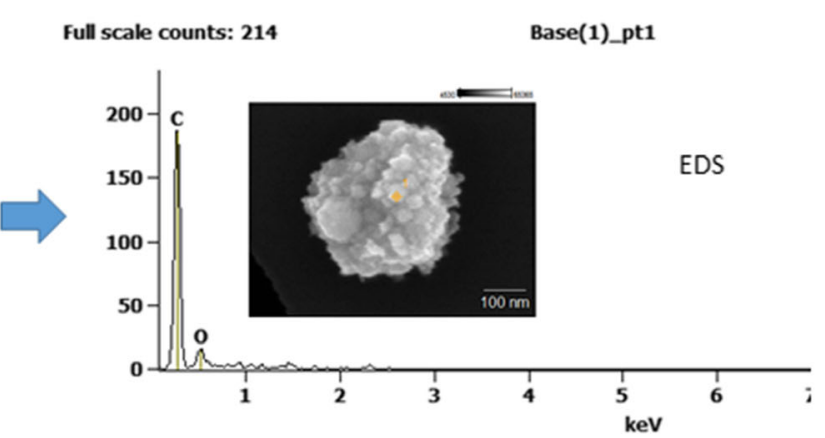



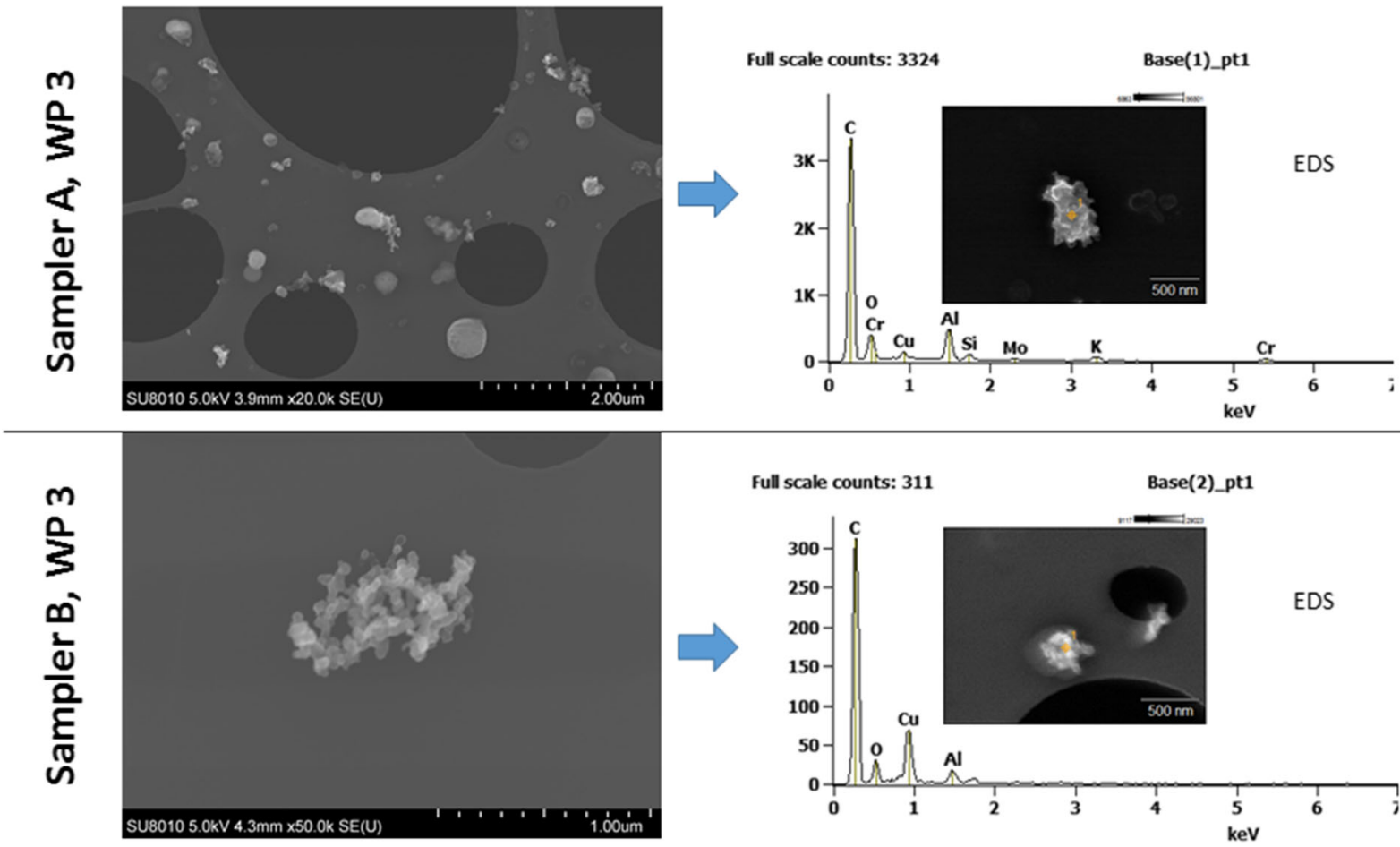

Fig. 11 SEM images and EDS analysis of samples collected at WP3
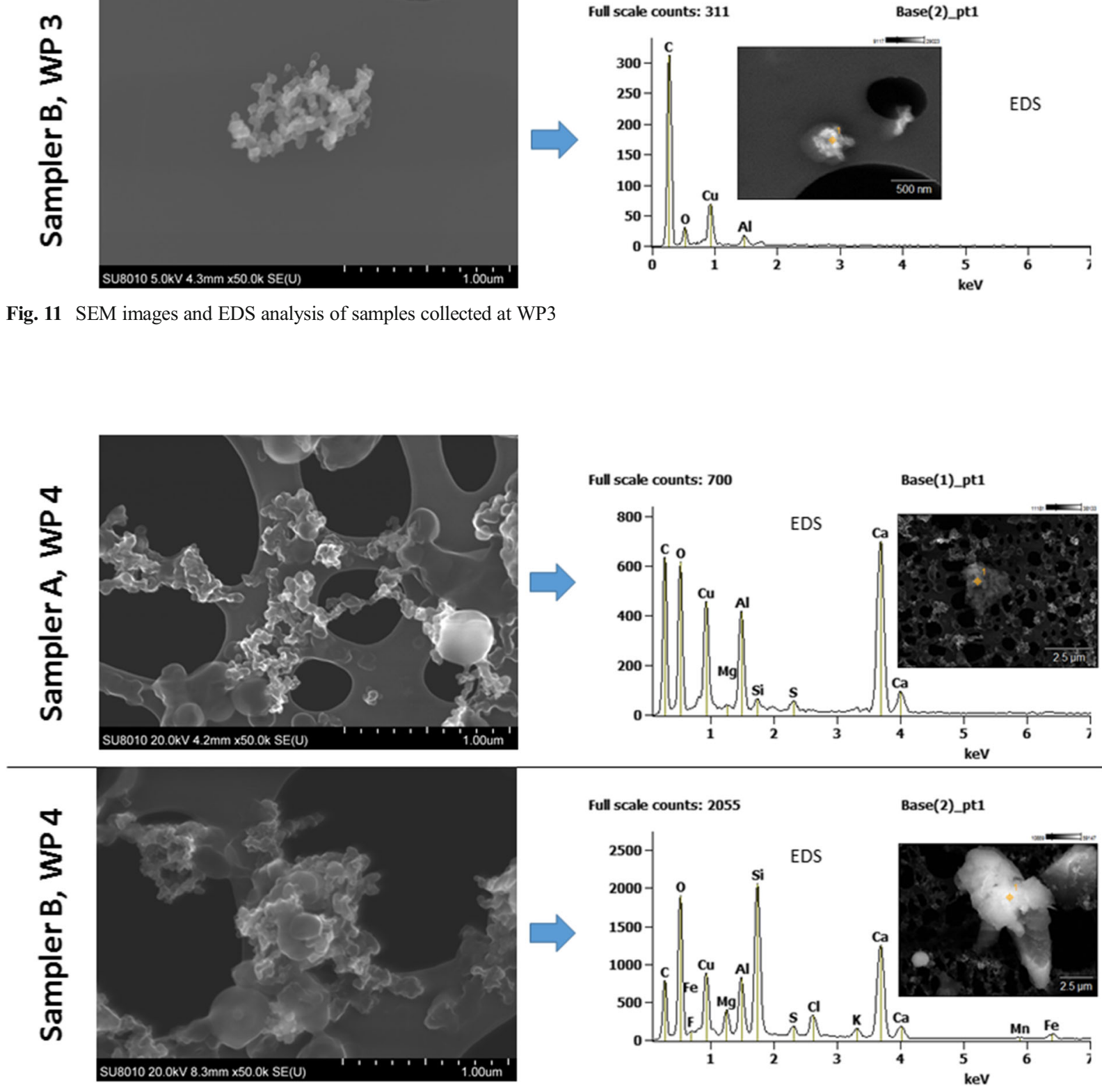

Fig. 12 SEM images and EDS analysis of samples collected at WP4

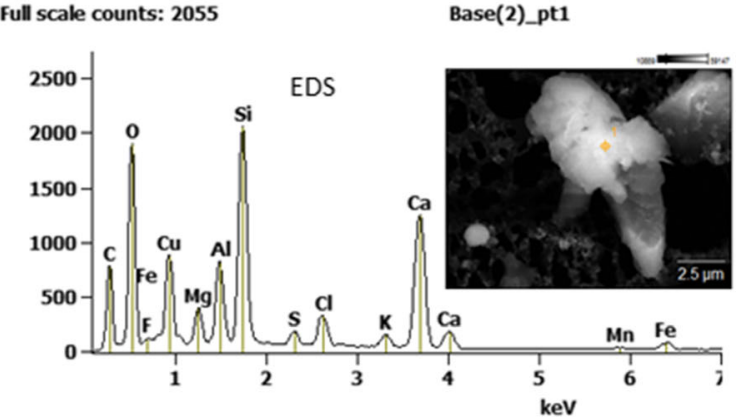


Table 5 Results of image analysis from SEM micrographs

\begin{tabular}{lllll}
\hline & WP1 & WP2 & WP3 & WP4 \\
\hline $\begin{array}{l}\text { Average particle size }(\mathrm{nm}) \\
\begin{array}{l}\text { Average size of agglomerates and/or aggregates } \\
(\min \text { to } \max )(\mu \mathrm{m})\end{array}\end{array}$ & $\begin{array}{c}46.7 \pm 13.4 \\
1.21 \pm 1.37(0.39 \text { to } \\
5.34)\end{array}$ & $\begin{array}{c}19.8 \pm 4.8 \\
0.66 \pm 0.28(0.30 \text { to } \\
1.40)\end{array}$ & $\begin{array}{c}0.57 \pm 0.29(0.27 \text { to } \\
1.41)\end{array}$ & $\begin{array}{c}1.44 \pm 0.53(0.62 \text { to } \\
2.53)\end{array}$ \\
\hline
\end{tabular}

Monitoring of the size of agglomerates and/or aggregates of nanoparticles is very important. If such an object fits into the size range of this fraction, there is a greater chance of it penetrating deep into the lower respiratory tract. Examples of agglomerates and/or aggregates (with marked length) collected at workplaces are presented in Fig. 13.

Environmental conditions and results of respirable dust fraction measurements

Averaged air parameters, respirable fraction and background levels recorded at four locations are presented in Table 6 . The values for pressure, temperature, humidity and speed of air were similar at each site and had no significant effect on concentrations, but they are important in showing the conditions prevailing during measurements and rejecting their effect on measurements.

\section{Discussion}

Measurements were conducted in 4 different workplaces in Polish companies where various processes were conducted. The concentration profiles of NOAA varied depending on the locations and activities carried out. There were no major fluctuations in pressure, temperature and relative humidity in the workplaces (Table 6).

DM-As were always placed closer to the worker, outside protective chambers and coveralls, and DM-Bs were placed as close to the process as possible. Very large differences are visible in the background levels between locations. At WP1 and WP2, the background levels were average for indoor areas, while at WP3 the background was extremely low, which was probably the result of high cleanliness and very efficient ventilation of a modern laboratory area. On the other hand, the background level at location WP4 was high, which could have been caused by large, urban outdoor air pollution.
A nanostructured object getting into the body poses a greater health risk than an analogous microstructured object, mostly due to the more developed surface, higher reactivity and the chance to release individual nanoparticles. The studies pertained to the possible emission of nanoparticles (and their aggregates and/or agglomerates) of carbon, amorphous silicon dioxide, hydroxyapatite and silver. There is no official OEL for nano silicon dioxide. On the basis of research results, in the European Project Scaffold report, Stockmann-Juvala et al., (Helene Stockmann-Juvala and Santonen 2014) suggested that $8 \mathrm{~h}$ OEL for respirable fraction of amorphous silicon dioxide (synthetic amorphous silica) should be $300 \mu \mathrm{g} / \mathrm{m}^{3}$. There is also no official OEL for carbon black and nanohydroxyapatite. NIOSH recommended to use respirable fraction less than $1 \mu \mathrm{g} / \mathrm{m}^{3}$ only for CNTs and carbon nanofibres (NIOSH 2013), but gave no recommendations for carbon black. WHO mentioned that for silver nanoparticles, various studies have shown "an evidence of a hazard for respiratory/skin sensitization and specific target organ toxicity after repeated exposure". There was no evidence for acute toxicity, skin corrosion, eye damage, germ cell mutagenicity and reproductive toxicity, and there was no data for carcinogenicity and specific target organ toxicity after single exposure incident. According to the WHO report, there are six mass concentration proposals in literature for nanosilver varying from 0.098 up to $10 \mu \mathrm{g} / \mathrm{m}^{3}$ (WHO 2017). Despite the confirmed presence of nanostructured objects that fit into the size range of the respirable fraction, it is worth to note the small mass concentration of this fraction collected at all studied workplaces (Table 6).

Based on NRV levels the number concentration of nanosilver in a work environment should not exceed 20,000 particles $/ \mathrm{cm}^{3}$; for carbon black and nano $\mathrm{SiO}_{2}$, safe level is below 40,000 particles $/ \mathrm{cm}^{3}$. For nanohydroxyapatite particles with density lower than $6 \mathrm{~g} / \mathrm{cm}^{3}\left(2.9 \mathrm{~g} / \mathrm{cm}^{3}\right)$, safe number concentration level is also below 40,000 particles $/ \mathrm{cm}^{3}$ (see "Recommended safe exposure levels for NOAA"). 


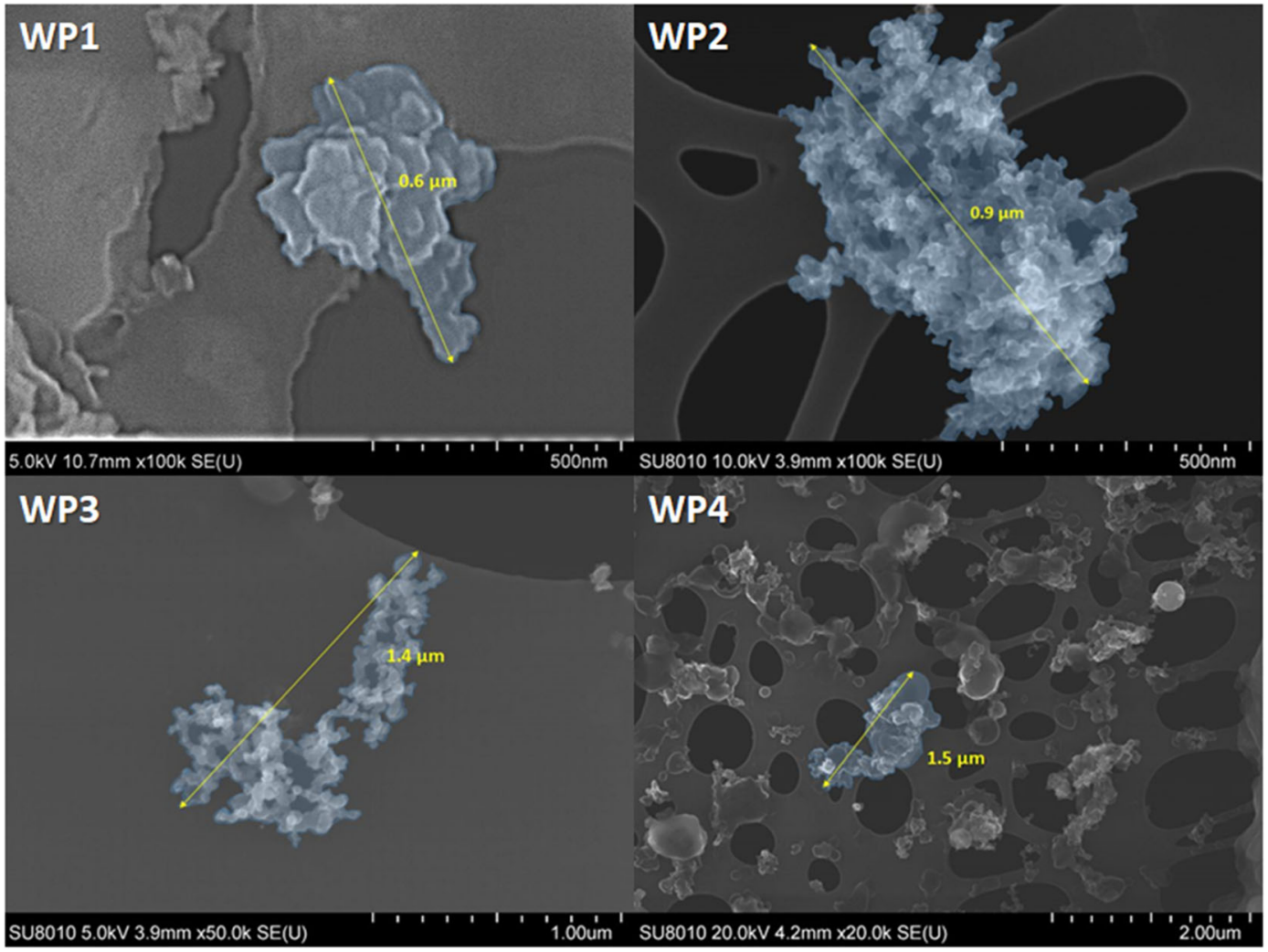

Fig. 13 Example of nanostructured objects (with marked length) collected at workplaces; from WP1 to WP4

Due to different environmental conditions, types of processes and even geographic locations, the results from the task-based assessment at each workstation should be interpreted separately.

Discussion of results from WP1-laser cutting of boron-aluminium silicate glass

The recorded concentration of unintentionally produced ultrafine particles exceeded 40,000 particles $/ \mathrm{cm}^{3}$ for about $50 \mathrm{~min}$ (11:45-12:35), the increase in concentration during processes over the background particle concentration was significant. Slow drop of the number concentration of particles was a result of general ventilation with low efficiency.

The low peaks $(a, b, c)$ occurred during the initial processes: weighing, pouring the dusty substance into the crucible, and inserting the material into the mixer, as well as during two separate processes of automatic cutting with a laser cutter. When the first peak (a) appeared, the employee opened a long drawer with a brush and parts of old foils. The second peak (b) also occurred during minor operations at the drawer. A significant, but narrow peak (j) also appeared at the end of work, during spraying the surface with silicone (in preparation for the next day's work).

Table 6 Environmental parameters and respirable fraction at studied locations

\begin{tabular}{lllll}
\hline & WP1 & WP2 & WP3 & WP4 \\
\hline Pressure $(\mathrm{hPa})$ & $1002.15 \pm 0.07$ & $1002.13 \pm 0.72$ & $1004.87 \pm 0.47$ & $998.67 \pm 0.12$ \\
Temperature $\left({ }^{\circ} \mathrm{C}\right)$ & $23.75 \pm 0.35$ & $26.10 \pm 0.80$ & $22.37 \pm 0.31$ & $23.77 \pm 0.58$ \\
Humidity $(\%)$ & $45.30 \pm 1.97$ & $44.90 \pm 2.70$ & $50.65 \pm 2.05$ & $35.07 \pm 0.50$ \\
Speed $(\mathrm{m} / \mathrm{s})$ & $0.03 \pm 0.01$ & $0.02 \pm 0.01$ & $0.09 \pm 0.02$ & $0.01 \pm 0.01$ \\
Respirable fraction $\left(\mathrm{mg} / \mathrm{m}^{3}\right)$ & $6.30 \times 10^{-3}$ & $2.90 \times 10^{-6}$ & $1.91 \times 10^{-5}$ & $8.20 \times 10^{-3}$ \\
\hline
\end{tabular}


High peaks $(e, f, h)$ occurred during manual work (drawer was opened once again) on the foils removed from the cutter. High concentration was associated with the cleaning (dust from the so-called tanning) and removing the cut-out form. Poor ventilation could allow for prolonged persistence of nano-objects in the air.

LDSA during high peaks (e, g, h) recorded by DM-A exceeded $100 \mu \mathrm{m}^{2} / \mathrm{cm}^{3}$. Long-lasting high concentration of NOAA at the peak moment reached nearly $1,500,000$ particles $/ \mathrm{cm}^{3}$ and posed a threat to the health of the employee.

SEM and EDS analysis confirmed the presence of boron, aluminium and silicon in the collected samples, which confirms their emission from the manufactured product or its intermediates. Results of this study influenced subsequent changes in the process, general protection and the introduction of additional personal protective equipment (PPE) at the workplace. Objects found on SEM micrographs were mainly aggregated nanoparticles with an elongated shape and average length $=46.7 \pm 13.4 \mathrm{~nm}$. Nanostructured aggregates ranged from 0.39 to $5.34 \mu \mathrm{m}$.

The NOAA size range of 36.9 to $72.8 \mathrm{~nm}$ recorded by DM-B (close to the laser cutting station) was larger than NOAA size range of 37.3 to $103.6 \mathrm{~nm}$, recorded by DM-A (close to the manual processing station). The diameter determined using image analysis was within the size range indicated by DiSCmini instruments and close to average size from DM-A $(51.08 \pm 9.46 \mathrm{~nm})$ and DM-B $(57.91 \pm 16.51 \mathrm{~nm})$.

Discussion of results from WP2 - generation of a thin nanocarbon layers

During the studied process, the concentration of nanoobjects outside the protective chamber did not even exceed 20,000 particles $/ \mathrm{cm}^{3}$ (DM-A), while according to adopted reference values safe level for carbon black is 40,000 particles $/ \mathrm{cm}^{3}$. The increase in concentration during the process over the background particle concentration was not significant as per the DM-A readings. On the profile obtained with DM-B, inside the protective chamber the concentration exceeded 20,000 only once for a short time (peak b). According to the DM-B readings, the increase in the concentration was significant during five events (peaks b, c, d, e, f). Wide concentration peak, beginning at event $\mathrm{d}$ (11:30-12:30) may have resulted from a leakage in the installation. The high concentrations were recorded only in the protective chamber and did not pose a threat to the worker, except during the opening of the chamber and manual cleaning of the generator with changing of electrodes.

LDSA exceeded $40 \mathrm{\mu m}^{2} / \mathrm{cm}^{3}$ only for few minutes during the manual cleaning of the generator and should not pose a health risk to the employee, but the activity should be considered by the worker and conducted with proper PPE.

Microscopic analysis showed that collected samples contained only aggregates and agglomerates of carbon compounds. However, the EDS method is not applicable for qualitative analysis in the case of carbon and lighter elements. It is worth noting that no other elements and impurities were found. Agglomerates and aggregates found in the collected samples were composed of spherical nanoparticles of average size $=19.8$ $\pm 4.8 \mathrm{~nm}$. Size of agglomerates and aggregates ranged from 0.30 to $1.40 \mu \mathrm{m}$.

Average NOAA sizes recorded by the DiSCmini devices were similar: $65.25 \pm 6.28 \mathrm{~nm}$ (DM-A) and $64.61 \pm 14.30 \mathrm{~nm}$ (DM-B), but some bigger NOAA were recorded by DM-B. DiSCmini B was closer to the source and inside the protective chamber (NOAA size range of 38.8 to $210.3 \mathrm{~nm}$ inside; a worker declared that an average size of generated nanoparticles should be in a range from about 50 to $150 \mathrm{~nm}$ ). DM-A did not record such big objects outside the chamber (NOAA size range of 44.2 to $88.8 \mathrm{~nm}$ ). These results support the occurrence of smaller NOAA from the enclosed process in the surrounding.

The nanoparticle sizes estimated by SEM image analysis were significantly smaller than the DiSCmini indicated. Probably, DiSCmini devices recorded more aggregates as single particles.

Discussion of results from WP3-3D-printing with a composite containing nanohydroxyapatite

NOAA concentration did not exceed the assumed safe level of 40,000 particles $/ \mathrm{cm}^{3}$. Moreover, the concentration did not even exceed 500 particles $/ \mathrm{cm}^{3}$. Such a low concentration was influenced by a very high room cleanliness, efficient mechanical ventilation, the insulated, automatic printing process and strong bonding of the hydroxyapatite nanoparticles with the polymer in the composite.

The increase in the concentration over the average background level was only significant on the profile 
obtained from DM-A, but it did not exceed the standard deviation of background concentration, which means these increases cannot be, in practice, distinguished from the background fluctuations. In addition, there were peaks at very low concentration values. The profile from DM-B has only one significant peak (g), the value of which is slightly higher than the standard deviation, and results from the movement of employees in the room, switching off the equipment and cleaning after the process. There was no significant difference between the readings from DiSCmini devices in the air outside and inside the protective chamber.

The reason for which the concentration of background NOAA and was greater than the concentration values during processes may be the operation of additional ventilation of the device associated with the process (3D-printer).

The LDSA was extremely low and did not exceed $2 \mu \mathrm{m}^{2} / \mathrm{cm}^{3}$. The average NOAA sizes were not calculated by DiSCmini devices due to the concentration of recorded objects being too low.

SEM and EDS analysis showed a mixture of nanoand microsized environmental dust. NOAA constituted mostly of agglomerates composed of spherical and slightly elongated nanoparticles with an average size of $22.4 \pm 7.6 \mathrm{~nm}$ (average size of the nanohydroxyapatite declared by a powder manufacturer was about $32 \mathrm{~nm}$ ). Nanostructured agglomerates ranged from 0.27 to $1.41 \mu \mathrm{m}$. There were no traces of calcium or phosphate in the samples, which could indicate NOAA emissions from the process or material.

Discussion of results from WP4 - chemical synthesis of silver nanoparticles

The recorded concentration of nano-objects (mainly from the background) exceeded 20,000 particles $/ \mathrm{cm}^{3}$. However, there was no significant increase in the NOAA concentration during the work process in relation to the background concentration. The area had a high background concentration before the start of the work and before turning on the mechanical ventilation, despite the presence of which it sustained for a considerable period of the main process. High background concentration was also reflected in respirable fraction value - the highest of all measured locations.

The size range of NOAA recorded by both DiSCmini devices was similar (66.2 to $72.7 \mathrm{~nm}$ from DM-A compared with 70.2 to $80.8 \mathrm{~nm}$ recorded by DM-B) with a very narrow distribution of measured values. Probably, most of the nano-objects inside and outside of the fume hood were flowing in from urban pollution outside the building.

The reason for which the concentration of background NOAA and UFPs was greater than the concentration values during processes may be the operation of additional ventilation during the main process (active fume hood). At the same time, significant air pollution was noted outside the building.

Only one peak (c, recorded by DM-B) exceeded the background level, but it was not significant in comparison with the standard deviation of the background concentration. High presence of background particles can impact the NOAA emitted from the process or incidental sources due to heterogeneous coagulation, described by Ono-Ogasawara et al. (Ono-Ogasawara et al. 2009). Therefore, paradoxically, the high content of background particles can have a neutralizing effect on emitted ENMs. Recorded LDSA in all cases except for one peak (d; DM-A, 82.81, $100 \mu \mathrm{m}^{2} / \mathrm{cm}^{3}$ ) exceeded $100 \mathrm{\mu m}^{2} / \mathrm{cm}^{3}$.

SEM and EDS analysis showed a mixture of nano and micro dust from environmental pollution. No traces of silver were recorded. Aggregates with nanostructure found on SEM micrographs ranged from 0.62 to $2.53 \mu \mathrm{m}$. An average size of the silver nanoparticles produced in the process should be around $50 \mathrm{~nm}$ as declared by a worker. Nanoparticles found on the SEM images were elongated with average size of $49.2 \pm$ $26.3 \mathrm{~nm}$.

Similar average particle sizes were recorded by DMA $(69.74 \pm 1.50 \mathrm{~nm})$ and DM-B $(76.03 \pm 2.01 \mathrm{~nm})$, but their standard deviation was very low. As mentioned earlier, this may indicate the surrounding area to be a homogeneous source of NOAA.

\section{Conclusion}

The objective of this study was to investigate the actual levels of exposure to nano-objects in real working conditions using a task-based approach and to get contextual data from research. Methodology, measurements and interpretations were based on the ISO/TS 12901 recommendations.

Major findings of present work are as follows: (1) even though research concerned mainly small-scale manufacturing, inhalation exposure to nano-objects still 
can occur, (2) there was a good agreement in the recorded average size by DiSCmini devices and SEM image analysis, (3) mostly agglomerates and aggregates were found in the collected aerosol samples and some of them were of a size matching the respirable fraction, (4) studies have shown that the ISO/TS 12901 method for determining exposure based on the background particle concentration is not suitable for very polluted areas. For exposure determination EN 16966 and EN 17058 should be used as supporting documents. It is also very important to relate the results to the recommended values and, hence, to intensify the work on determination of the threshold values for NOAA.

Moreover, the studies have shown the importance of collective protection measures (ventilation), revealed the unexpected sources of accidentally generated nanoobjects and supplemented the knowledge on levels of exposure to nanoparticles during various stages of performed activities. Based on the obtained results, monitoring of the manual tasks seems to be of as significant importance as the other activities.

Acknowledgements The authors wish to thank the Nanonet Foundation for help in contact with nanotechnology companies in Poland.

Author's contributions All authors contributed substantially to the concept and methodology of the study, drafting of the article and critical revision of the manuscript for intellectual content. All authors have read and approved the final version of the manuscript for publication.

Funding information This paper has been based on the results of a research task 4.G.04 carried out within the scope of the fourth stage of the National Programme "Improvement of safety and working conditions" partly supported in 2017-2019 — within the scope of state services - by the Ministry of Labour and Social Policy. The Central Institute for Labour Protection - National Research Institute is the Programme's main co-ordinator.

\section{Compliance with ethical standards}

Conflict of interest The authors declare that they have no conflicts of interest.

Open Access This article is distributed under the terms of the Creative Commons Attribution 4.0 International License (http:// creativecommons.org/licenses/by/4.0/), which permits unrestricted use, distribution, and reproduction in any medium, provided you give appropriate credit to the original author(s) and the source, provide a link to the Creative Commons license, and indicate if changes were made.

\section{References}

ACGIH (2018) 2018 TLVs and BEIs. American Conference of Governmental Industrial Hygienists

Al-Sid-Cheikh M, Rowland SJ, Stevenson K, Rouleau C, Henry TB, Thompson RC (2018) Uptake, whole-body distribution, and depuration of nanoplastics by the scallop Pecten maximus at environmentally realistic concentrations. Environ Sci Technol 52:14480-14486. https://doi. org/10.1021/acs.est.8b05266

Branche CM (2009) Approaches to safe nanotechnology: managing the health and safety concerns associated with engineered nanomaterials. DHHS (NIOSH) Publication Number 2009125

Broekhuizen P, Hendrikx B (2013) Nano reference values in the Netherlands vol 73

Brouwer D (2012) Control banding approaches for nanomaterials vol 56. https://doi.org/10.1093/annhyg/mes039

Brouwer D, van Duuren-Stuurman B, Berges M, Jankowska E, Bard D, Mark DJJoNR (2009) From workplace air measurement results toward estimates of exposure? Development of a strategy to assess exposure to manufactured nano-objects $\mathrm{J}$ Nanopart Res 11:1867 https://doi.org/10.1007/s11051-0099772-1, 1881

Brouwer D et al (2013) Workplace air measurements and likelihood of exposure to manufactured nano-objects, agglomerates, and aggregates vol 15. https://doi.org/10.1007/s11051013-2090-7

Brown DM, Wilson MR, MacNee W, Stone V, Donaldson K (2001) Size-dependent proinflammatory effects of ultrafine polystyrene particles: a role for surface area and oxidative stress in the enhanced activity of ultrafines. Toxicol Appl Pharmacol 175:191-199. https://doi.org/10.1006 /taap.2001.9240

BSI (2007) Guide to safe handling and disposal of manufactured nanomaterials. Nanotechnologies - part 2 vol PD 6699-2: 2007. British Standards Institution

Buzea C, Pacheco II, Robbie K (2007) Nanomaterials and nanoparticles: sources and toxicity. Biointerphases 2: Mr17-Mr71

CEN (2018a) Workplace exposure - assessment of exposure by inhalation of nano-objects and their aggregates and agglomerates vol EN 17058:2018. European Committee for Standardization

CEN (2018b) Workplace exposure - measurement of exposure by inhalation of nano-objects and their aggregates and agglomerates - metrics to be used such as number concentration, surface area concentration and mass concentration vol EN 16966:2018

Cheng L-C, Jiang X, Wang J, Chen C, Liu R-S (2013) Nano-bio effects: interaction of nanomaterials with cells. Nanoscale 5: 3547-3569. https://doi.org/10.1039/C3NR34276J

Dastjerdi R, Montazer M (2010) A review on the application of inorganic nano-structured materials in the modification of textiles: focus on anti-microbial properties. Colloids Surf B Biointerfaces 79:5-18. https://doi.org/10.1016/j. colsurfb.2010.03.029

De Jong WH, Borm PJA (2008) Drug delivery and nanoparticles: applications and hazards. Int J Nanomed 3:133-149 
Definition of a nanomaterial (2017) http://ec.europa. eu/environment/chemicals/nanotech/faq/definition_en.htm

Deveau M et al (2015) The global landscape of occupational exposure limits - implementation of harmonization principles to guide limit selection. J Occup Environ Hyg 12: S $127-$ S 144 . https://doi org/10.1080 /15459624.2015.1060327

DFG (2011) New threshold values for fine particulates at the workplace vol Press Release No. 37. Deutsche Forschungsgemeinschaft

Dolez PI (2015) Chapter 1.1 - Nanomaterials definitions, classifications, and applications. In: Dolez PI (ed) Nanoengineering. Elsevier, Amsterdam, pp 3-40. https://doi.org/10.1016 /B978-0-444-62747-6.00001-4

Dreaden EC, Austin LA, Mackey MA, El-Sayed MA (2012) Size matters: gold nanoparticles in targeted cancer drug delivery. Ther Deliv 3:457-478

EC (2014) Guidance on the protection of the health and safety of workers from the potential risks related to nanomaterials at work. European Commission

Ellenbecker M, Tsai SJ, Jacobs M, Riediker M, Peters T, Liou S, Avila A, FossHansen S (2018) The difficulties in establishing an occupational exposure limit for carbon nanotubes. J Nanopart Res 20:131. https://doi.org/10.1007/s11051-0184221-7

EU (2011) Commission recommendation of 18 October 2011on the definition of nanomaterial (2011/696/EU). Official Journal of the European Union

Fierz M, Houle C, Steigmeier P, Burtscher H (2011) Design, Calibration, and field performance of a miniature diffusion size classifier. Aerosol Sci Technol 45:1-10. https://doi. org/10.1080/02786826.2010.516283

Firdhouse MJ, Lalitha P (2015) Biosynthesis of silver nanoparticles and its applications. J Nanotechnol 2015:18. https://doi. org/10.1155/2015/829526

Gajanan K, Tijare SN (2018) Applications of nanomaterials. Mater Today Proc 5:1093-1096. https://doi.org/10.1016/j. matpr.2017.11.187

Geiss O, Bianchi I, Barrero-Moreno J (2016) Lungdeposited surface area concentration measurements in selected occupational and non-occupational environments. J Aerosol Sci 96:24-37. https://doi.org/10.1016 /j.jaerosci.2016.02.007

Geza Benke MD, Priestly B, Sim M, Morris H (2010) Engineered nanomaterials: feasibility of establishing exposure standards and using control banding in Australia. Safe Work Australia's Nanotechnology OHS Advisory Group, and Nanotechnology OHS Measurement Reference Group

Gomez V, Irusta S, Balas F, Navascues N, Santamaria J (2014) Unintended emission of nanoparticle aerosols during common laboratory handling operations. J Hazard Mater 279:7584. https://doi.org/10.1016/j.jhazmat.2014.06.064

HEI (2013) Understanding the health effects of ambient ultrafine particles vol HEI perspective 3. Massachusetts, Boston

Helene Stockmann-Juvala PT, Santonen T (2014) Formulating occupational exposure limits values (OELls) (inhalation \& dermal)

Heyder J (2004) Deposition of inhaled particles in the human respiratory tract and consequences for regional targeting in respiratory drug delivery. Proc Am Thorac Soc 1:315-320. https://doi.org/10.1513/pats.200409-046ta
Heyder J, Gebhart J, Rudolf G, Schiller CF, Stahlhofen W (1986) Deposition of particles in the human respiratory tract in the size range 0.005-15 $\mu \mathrm{m}$. J Aerosol Sci 17:811-825. https://doi.org/10.1016/0021-8502(86)90035-2

Hoet PHM, Brüske-Hohlfeld I, Salata OV (2004) Nanoparticles known and unknown health risks. J Nanobiotechnol 2:12. https://doi.org/10.1186/1477-3155-2-12

ICRP ICfRP (1994) Respiratory tract model vol 24. SAGE Publications Ltd 24:1-11. https://doi.org/10.1016/01466453(94)90004-3

ISO (2012a) ISO (2012) 13138:2012 air quality — sampling conventions for airborne particle deposition in the human respiratory system. International Standard Organization

ISO (2012b) ISO/TS 12901-1:2012 nanotechnologies - occupational risk management applied to engineered nanomaterials - part 1: principles and approaches vol ISO/TS 12901-1: 2012. International Standard Organization

ISO (2014) ISO/TS 12901-2:2014 nanotechnologies - occupational risk management applied to engineered nanomaterials - part 2: used of the control banding approach vol ISO/TS 12901-2:2014. International Standard Organization

Jeevanandam J, Barhoum A, Chan YS, Dufresne A, Danquah MK (2018) Review on nanoparticles and nanostructured materials: history, sources, toxicity and regulations. Beilstein $\mathrm{J}$ Nanotechnol 9:1050-1074. https://doi.org/10.3762 /bjnano.9.98

Khanna P, Ong C, Bay BH, Baeg GH (2015) Nanotoxicity: an interplay of oxidative stress, inflammation and cell death. Nanomaterials (Basel, Switzerland) 5:1163-1180. https://doi.org/10.3390/nano5031163

Kumar P, Robins A, Vardoulakis S, Britter R (2010) A review of the characteristics of nanoparticles in the urban atmosphere and the prospects for developing regulatory controls. Atmos Environ 44:5035-5052. https://doi.org/10.1016/j. atmosenv.2010.08.016

Kuuluvainen $\mathrm{H}$ et al (2016) Lung deposited surface area size distributions of particulate matter in different urban areas. Atmos Environ 136:105-113. https://doi.org/10.1016/j. atmosenv.2016.04.019

Lavoie JH (2010) A review of nanomaterial safety concerns. Process Saf Prog 29:182-185. https://doi.org/10.1002 /prs. 10388

Ma-Hock L et al (2009) Inhalation toxicity of multiwall carbon nanotubes in rats exposed for 3 months. Toxicol Sci 112: 468-481. https://doi.org/10.1093/toxsci/kfp146

Mark D (2007) Chapter 4: Occupational exposure to nanoparticles and nanotubes. In: Nanotechnology: consequences for human health and the environment, vol 24. The Royal Society of Chemistry, pp 50-80. https://doi.org/10.1039 /9781847557766-00050

Maynard AD, Aitken RJ (2007) Assessing exposure to airborne nanomaterials: current abilities and future requirements. Nanotoxicology 1:26-41. https://doi.org/10.1080 $/ 17435390701314720$

Mc Carthy D, Malhotra M, Aoife OM, Cryan J, O’Driscoll C (2015) Nanoparticles and the blood-brain barrier: advancing from in-vitro models towards therapeutic significance. Pharm Res 32:1161-1185. https://doi.org/10.1007/s11095-014$1545-6$ 
Mihalache R, Verbeek J, Graczyk H, Murashov V, van Broekhuizen P (2017) Occupational exposure limits for manufactured nanomaterials, a systematic review. Nanotoxicology 11:7-19. https://doi.org/10.1080 $/ 17435390.2016 .1262920$

NECID (2018) http://www.perosh.eu/research-projects/peroshprojects/necid/

Nel A, Xia T, Madler L, Li N (2006) Toxic potential of materials at the nanolevel. Science 311:622-627. https://doi.org/10.1126 /science.1114397

NIOSH (2011) Approaches to safe nanotechnology: document provides guidance to protect nanotechnology workers. The National Institute for Occupational Safety and Health. https:/www.cdc.gov/niosh/docs/2011-206/

NIOSH (2013) Occupational exposure to carbon nanotubes and nanofibers vol 65. National Institute for Occupational Safety and Health

Nogueira DR, Mitjans M, Rolim CMB, Vinardell MP (2014) Mechanisms underlying cytotoxicity induced by engineered nanomaterials: a review of in vitro studies. Nanomaterials (Basel, Switzerland) 4:454-484. https://doi.org/10.3390 /nano4020454

O'Shaughnessy PT (2013) Occupational health risk to nanoparticulate exposure. Environ Sci Process Impacts 15: 49-62

Oberbek P (2018) NECID - nano exposure and contextual information database vol 35. https://doi.org/10.5604 /01.3001.0012.1018

Oberdörster G, Ferin J, Gelein R, Soderholm SC, Finkelstein J (1992) Role of the alveolar macrophage in lung injury: studies with ultrafine particles. Environ Health Perspect 97: 193-199. https://doi.org/10.1289/ehp.97-1519541

Oberdörster G, Oberdörster E, Oberdörster J (2005) Nanotoxicology: an emerging discipline evolving from studies of ultrafine particles. Environ Health Perspect 113:823839. https://doi.org/10.1289/ehp.7339

OECD (2017) Strategies, techniques and sampling protocols for determining the concentrations of manufactured nanomaterials in air at the workplace, series on the safety of manufactured nanomaterials vol 82. Organisation for Economic Co-operation and Development

Ono-Ogasawara M, Serita F, Takaya MJ (2009) Distinguishing nanomaterial particles from background airborne particulate matter for quantitative exposure assessment. J Nanopart Res 11:1651-1659. https://doi.org/10.1007/s11051-009-9703-1

Pauluhn J (2010a) Multi-walled carbon nanotubes (Baytubes): approach for derivation of occupational exposure limit. Regul Toxicol Pharmacol 57:78-89. https://doi.org/10.1016 /j.yrtph.2009.12.012

Pauluhn J (2010b) Subchronic 13-week inhalation exposure of rats to multiwalled carbon nanotubes: toxic effects are determined by density of agglomerate structures, not fibrillar structures. Toxicol Sci 113:226-242. https://doi.org/10.1093 /toxsci/kfp247

Prasad R, Bhattacharyya A, Nguyen QD (2017) Nanotechnology in sustainable agriculture: recent developments, challenges, and perspectives. Front Microbiol 8:1014-1014. https://doi. org/10.3389/fmicb.2017.01014

Ramachandran G et al (2011) A strategy for assessing workplace exposures to nanomaterials. J Occup Environ Hyg 8:673685. https://doi.org/10.1080/15459624.2011.623223
Ramos AP, Cruz MAE, Tovani CB, Ciancaglini P (2017) Biomedical applications of nanotechnology. Biophys Rev 9:79-89. https://doi.org/10.1007/s12551-016-0246-2

Salata OV (2004) Applications of nanoparticles in biology and medicine. J Nanobiotechnol 2:3. https://doi.org/10.1186 /1477-3155-2-3

SCENIHR (2007) The appropriateness of the risk assessment methodology in accordance with the Technical Guidance Documents for new and existing substances for assessing the risks of nanomaterials. Scientific Committee on Emerging and Newly Identified Health Risks, European Commission, Brussels

Schulte PA, Murashov V, Zumwalde R, Kuempel ED, Geraci CL (2010) Occupational exposure limits for nanomaterials: state of the art. J Nanopart Res 12:1971-1987. https://doi. org/10.1007/s11051-010-0008-1

Schumacher C, Pallapies D (2009) Criteria for assessment of the effectiveness of protective measures. IFA DGUV. https://www.dguv.de/ifa/fachinfos/nanopartikel-amarbeitsplatz/beurteilung-von-schutzmassnahmen/index-2.jsp

Seipenbusch M, Binder A, Kasper G (2008) Temporal evolution of nanoparticle aerosols in workplace exposure vol 52 . https://doi.org/10.1093/annhyg/men067

Seixas NS, Sheppard L, Neitzel R (2003) Comparison of taskbased estimates with full-shift measurements of noise exposure. AIHA J (Fairfax, VA) 64:823-829. https://doi. org/10.1202/524.1

Simcha S, Dotan A, Kenig S, Dodiuk H (2012) Characterization of hybrid epoxy nanocomposites. Nanomaterials (Basel, Switzerland) 2:348-365. https://doi.org/10.3390 /nano2040348

Singh S, Nalwa HS (2007) Nanotechnology and health safetytoxicity and risk assessments of nanostructured materials on human health. J Nanosci Nanotechnol 7:3048-3070

Sobot D, Mura S, Couvreur P (2014) Nanoparticles: blood components interactions. In: Kobayashi S, Müllen K (eds) Encyclopedia of polymeric nanomaterials. Springer Berlin Heidelberg, Berlin, Heidelberg, pp 1-10. https://doi. org/10.1007/978-3-642-36199-9_227-1

Świdwińska-Gajewska AM, Czerczak S (2014) Titanium dioxide nanoparticles: occupational exposure limits. Med Pr 65:407418. https://doi.org/10.13075/mp.5893.2014.046

Świdwińska-Gajewska AM, Czerczak S (2015) Nanosilver - occupational exposure limits. Med Pr 66:429-442. https://doi. org/10.13075/mp.5893.00177

Terentyuk G (2009) Tracking gold nanoparticles in the body. https://doi.org/10.1117/2.1200907.1619

van Broekhuizen P, van Veelen W, Streekstra WH, Schulte P, Reijnders L (2012) Exposure limits for nanoparticles: report of an international workshop on nano reference values. Ann Occup Hyg 56:515-524. https://doi.org/10.1093 /annhyg/mes043

Waseda Y, Muramatsu A (2013) Morphology control of materials and nanoparticles: advanced materials processing and characterization. Springer, Berlin Heidelberg

WHO (2017) WHO Guidelines on protecting workers from potential risks of manufactured nanomaterials

Xie W, Weidenkaff A, Tang X, Zhang Q, Poon J, Tritt TM (2012) Recent advances in nanostructured thermoelectric halfHeusler compounds. Nanomaterials (Basel, Switzerland) 2: 379-412. https://doi.org/10.3390/nano2040379 
Zhang Z, Zhang L, Hedhili MN, Zhang H, Wang P (2013)

Plasmonic gold nanocrystals coupled with photonic crystal seamlessly on $\mathrm{TiO} 2$ nanotube photoelectrodes for efficient visible light photoelectrochemical water splitting. Nano Lett 13:14-20. https://doi.org/10.1021/nl3029202
Publisher's note Springer Nature remains neutral with regard to jurisdictional claims in published maps and institutional affiliations. 